\title{
Activated carbon nanofibers from lignin/recycled-PET and their adsorption capacity of refractory sulfur compounds from fossil fuels
}

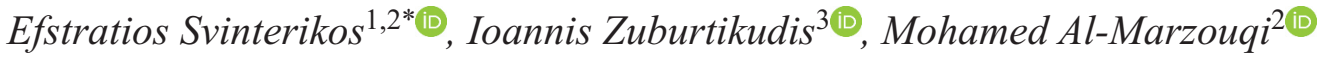 \\ ${ }^{1}$ Nanotypos, Technopoli ICT Business Park Thessaloniki, Building C2, 55535 Pylea, Greece \\ ${ }^{2}$ Department of Chemical and Petroleum Engineering, United Arab Emirates University (U.A.E.U.), 15551 Al Ain, U.A.E. \\ ${ }^{3}$ Department of Chemical Engineering, Abu Dhabi University, 59911 Abu Dhabi, U.A.E.
}

Received 19 August 2021; accepted in revised form 18 October 2021

\begin{abstract}
Carbon nanofibers (CNFs) from a blend of lignin with recycled poly(ethylene terephthalate) (r-PET) were produced from the thermal treatment of precursor electrospun lignin/r-PET nanofibrous mats. The impact of the lignin/r-PET mass ratio (ranging from 50/50 to 90/10) on the morphology, porosity and carbon structure of the CNFs was thoroughly investigated. The CNFs produced from a lignin/r-PET mass ratio of $50 / 50$ possess the highest BET surface area $\left(353 \mathrm{~m}^{2} / \mathrm{g}\right)$ as the presence of r-PET contributes to the development of microporosity, while all CNFs consist of disordered carbon structure. Their chemical activation with $\mathrm{KOH}$ boosted their BET surface area to $1413 \mathrm{~m}^{2} / \mathrm{g}$ and further treatment with $\mathrm{HNO}_{3}$ anchored oxygen functional groups on their surface. These activated CNFs were used for the adsorption of 4,6-dimethyldibenzothiophene (DMDBT) from a model diesel fuel (n-dodecane) and it was found that they exhibit a high adsorption capacity at ambient conditions $\left(120.3 \mathrm{mg}_{\mathrm{DMDBT}} / \mathrm{g}_{\mathrm{C}}\right)$. This is combined with remarkably fast adsorption kinetics as $94 \%$ of the equilibrium concentration is reached after just $1 \mathrm{~min}$. These outstanding kinetics are justified by the nano-structured morphology of the activated CNFs which translates into a very large specific surface area that minimizes mass transfer limitations.
\end{abstract}

Keywords: nanomaterials, processing technologies, lignin, recycled PET, carbon nanofibers

\section{Introduction}

The development of carbon nanomaterials from polymeric precursors has altered materials science and technology in recent decades, as these materials have shown the potential to upgrade many technological and industrial applications. In particular, carbon nanofibers (CNFs) are typically manufactured via the thermal treatment of precursor polymer nanofibers. They are a one-dimensional form of carbon with diameters in the nano- or in the submicron-scale, which have a wide range of potential engineering applications $[1,2]$.

A suitable technique for the fabrication of precursor polymer nanofibers is electrospinning and the most common polymer for this purpose is poly(acrylonitrile) (PAN) [1, 3, 4]. However, PAN is a petroleumderived polymer, therefore, alternative, sustainable precursors such as lignin have been used instead. Lignin is a very abundant plant-derived natural polymer and a major biorenewable source of aromatic structures [5, 6]. Although it is produced in considerable quantities as a major by-product of the paper industry, its large potential is still unexploited since most of it is burnt as a low-grade fuel [7]. Nevertheless, it is a suitable, biorenewable CNF precursor either alone or blended with a binder polymer such as PAN, polyvinyl alcohol (PVA) or polyethylene oxide (PEO) [8-11]. The presence of a binder polymer is 
important for the spinnability of the fibers. Our group was the first to produce electrospun-based CNFs from a blend of lignin with recycled poly(ethylene terephthalate) (r-PET) [12-14]. PET is a major component of municipal waste, so, using recycled PET for the manufacture of high added-value engineering materials such as CNFs will contribute to more efficient waste management.

CNFs consist of a continuous network of carbonaceous filaments with a possible degree of interconnection among them [15]. While carbon nanotubes are formed by wrapped concentric graphene layers, the structure of CNFs is more disordered, although $\mathrm{sp}^{2}$-hybridized carbon is prevalent, as well [2]. They typically contain graphitic regions which are built of planar graphene sheets stacked in parallel, inside a matrix of more randomly oriented, curved and defective graphene sheets $[2,16]$. The extent of ordered and disordered regions depends on the precursor materials and the method of production [13, 14]. The regions of randomly oriented, defective graphene sheets resemble the shape of crumpled paper (disordered carbon structure); this structure translates into significant porosity [17]. In this article, the porosity and the structure of lignin/r-PET CNFs are investigated with respect to the lignin/r-PET mass ratio, while the porosity characteristics and the morphology of activated CNFs (ACNFs) are further examined.

The nano-sized diameter of CNFs maximizes their specific surface area, which renders them suitable for a variety of applications, such as for the manufacture of electrodes for rechargeable batteries and supercapacitors, for polymer-based nanocomposites, in sensors and also in adsorption and catalysis applications $[2,8]$. Here, we examine their potential as desulfurization adsorbents for the removal of refractory sulfur compounds from fossil fuels. The sulfur compounds in commercial fuels pose a serious environmental concern as they are associated with air pollution and harmful effects on human health [18]. In the last 15 years, the competent authorities in most developed countries (USA, European Union, China, Japan and elsewhere) have regulated the maximum sulfur content of commercial fuels to $10 \mathrm{ppm}$ for gasoline and 10-15 ppm for diesel [19-21]. Especially, the heavier, aromatic sulfur compounds (termed as 'refractory sulfur compounds') such as 4,6-dimethyldibenzothiophene (DMDBT) are difficultly removed through the hydrodesulfurization method, which has been traditionally applied in most refineries for a long time. Hydrodesulfurization is a catalytic process that occurs at high temperatures and pressures $[22,23]$, and CNFs have been used in this process as support of transition metal catalysts [24, 25].

Nevertheless, alternative desulfurization methods at ambient temperatures and pressures have been proposed. Among these, adsorptive desulfurization has shown promising potential for this purpose either alone or in conjunction with other methods $[18,26]$. Electrospun-derived PVA-based CNFs have been previously applied to the adsorption of thiophene [27], while PAN-based CNFs have been tested for the adsorption of $\mathrm{H}_{2} \mathrm{~S}$, mercaptans [28], thiophene and benzothiophene [29, 30], but there has been no study up to now for the removal of heavier sulfur compounds from diesel, especially DMDBT, using these materials. Here, we prove that highly porous lignin/r-PET-based activated CNFs show a high adsorption capacity for refractory sulfur compounds from a model diesel fuel combined with outstanding adsorption kinetics.

\section{Materials and methods}

Kraft lignin (low sulfonate content, $M_{\mathrm{w}} \sim$ $10000 \mathrm{~g} / \mathrm{mol}$ ) was purchased from Sigma-Aldrich (\#471003) and it was used without modification. Waste water-bottles were used as the source of r-PET. All of them came from the same bottling company (Masafi) in the United Arab Emirates. Before the preparation of the spinnable solutions, the bottles were left to dry and then they were cut with scissors into pieces. Trifluoroacetic acid (TFA, 99\%, \#808260) purchased from Merck was used as the solvent for the electrospinning process. The solutions of lignin/ r-PET were prepared and left under magnetic stirring at room temperature for $12 \mathrm{~h}$ until homogeneously dissolved. High purity $\mathrm{N}_{2}(99.999 \%)$ was used in all the carbonization experiments. High purity $\mathrm{CO}_{2}$ (99.99\%) was used in the activation experiments. $\mathrm{HNO}_{3} 65 \%$ (\#84380-M), HCl 37\% (\#100317), bromothymol blue (\#103026), NaOH pellets (\#S5881) and $\mathrm{KOH}$ pellets (\#105033) were purchased from Sigma-Aldrich. For the adsorption experiments, 4,6dimethyldibenzothiophene (DMDBT, 97\%,\#479411) purchased from Sigma-Aldrich was used. N-dodecane $(99 \%$, \#D221104) was used as a model diesel fuel, and it was purchased from Honeywell-Riedel de Haen.

The electrospinning process was performed in a FUENCE Esprayer (ES-2000S) apparatus in which 
the setup has a vertical orientation. Electrospun precursor nanofibers were initially prepared from a 50/50 and a 90/10 lignin/r-PET mass ratio. The choice of these values is based on the demand for a wellformed filamentous carbon structure, as it is described in our previous publications $[12,13]$. The electrospun mats prepared from 50/50 lignin/r-PET mass ratio had $395 \pm 131 \mathrm{~nm}$ average fiber diameter, as it was not possible to prepare thinner well-formed CNFs at 50/50 lignin/r-PET mass ratio. The electrospun mats prepared from 90/10 lignin/r-PET had $116 \pm 32 \mathrm{~nm}$ average fiber diameter, the thinnest nanofibers prepared successfully. For the former, the electrospinning conditions were the following: the solution concentration (of both polymers in the solution) was $21 \% \mathrm{w} / \mathrm{v}$, the spinning distance was $20 \mathrm{~cm}$, the voltage was $30 \mathrm{kV}$ and the flow rate was $0.1 \mu \mathrm{l} / \mathrm{min}$. For the latter, the following conditions were applied: solution concentration $13 \% \mathrm{w} / \mathrm{v}$, spinning distance $7.7 \mathrm{~cm}$, voltage $30 \mathrm{kV}$ and flow rate $0.1 \mu \mathrm{l} / \mathrm{min}$.

The CNFs were prepared after the carbonization of the electrospun mats in a temperature-programmed tubular furnace (GSL-1500X-50, MTI). Each sample was heated under inert atmosphere $\left(\mathrm{N}_{2}\right)$ (flow rate $\sim 300 \mathrm{cc} / \mathrm{min}$ ) at a heating rate of $5{ }^{\circ} \mathrm{C} / \mathrm{min}$ until it reached $1000^{\circ} \mathrm{C}$, where it was held for $1 \mathrm{~h}$; then, it was allowed to cool down at the same inert atmosphere.

The activation of the CNFs was carried out using either physical activation with $\mathrm{CO}_{2}$ or chemical activation with $\mathrm{KOH}$. For all cases, CNFs carbonized at $1000^{\circ} \mathrm{C}$ were the starting materials. For the physical activation, the CNFs were crashed by fingers into smaller pieces, they were placed into a combustion boat and were transferred into the temperature-programmed tubular furnace (GSL-1500X-50, MTI). They were heated under $\mathrm{N}_{2}$ atmosphere at a rate of $5^{\circ} \mathrm{C} / \mathrm{min}$ until they reached $700^{\circ} \mathrm{C}$. Then, the atmosphere was switched to $\mathrm{CO}_{2}$ at a flow rate of 200$300 \mathrm{cc} / \mathrm{min}$ and they were held at this temperature for $1 \mathrm{~h}$. Finally, the gas was switched again to $\mathrm{N}_{2}$ and they were left to cool down. The ACNFs produced with physical activation are denoted as 'ACNFs50/50- $\mathrm{CO}_{2}$ ' and 'ACNFs-90/10- $\mathrm{CO}_{2}$ ' respectively for the two starting lignin/r-PET mass ratios (50/50 and 90/10) studied here.

For the chemical activation, only the CNFs derived from 50/50 lignin/r-PET with $395 \mathrm{~nm}$ average fiber diameter were used, after they were first crushed by fingers into powder. They were dispersed into a
$\mathrm{KOH} 3 \mathrm{M}$ solution at a mass ratio of $4 / 1 \mathrm{KOH} / \mathrm{CNFs}$, and they were left under stirring for $12 \mathrm{~h}$ at room temperature. Then, they were placed into a combustion boat and transferred into the tubular furnace, in which they were heated under $\mathrm{N}_{2}$ at a rate of $5^{\circ} \mathrm{C} / \mathrm{min}$ up to $800^{\circ} \mathrm{C}$, where they were held for $1 \mathrm{~h}$. Finally, they were left to cool down. Subsequently, they were dispersed in an excess of $\mathrm{HCl} 1 \mathrm{M}$ solution under stirring to neutralize the remaining $\mathrm{KOH}$, and they were repeatedly washed with de-ionized water and filtered via membrane filtration (Millipore membrane filter $0.22 \mu \mathrm{m}$ ) until the filtrate had $\mathrm{pH} \sim 7$. Finally, they were dried overnight at $130^{\circ} \mathrm{C}$. This sample is denoted as 'ACNFs-KOH'. Some of the ACNFs-KOH were further treated with $\mathrm{HNO}_{3}$. First, they were dispersed into $\mathrm{HNO}_{3} 4 \mathrm{M}(0.8 \mathrm{~g}$ per $100 \mathrm{ml}$ solution) and they were left under stirring at $90^{\circ} \mathrm{C}$ for $8 \mathrm{~h}$. Then, they were repeatedly washed with deionized water and filtered through membrane filtration (Millipore membrane filter $0.22 \mu \mathrm{m}$ ) until the filtrate had a $\mathrm{pH}$ of $\sim 7$. Finally, they were dried overnight at $130^{\circ} \mathrm{C}$. This sample is denoted as 'ACNFs-KOH-HNO${ }_{3}$ '.

The morphology of the fibrous mats was examined via Scanning Electron Microscopy (SEM) after goldcoating them. The average fiber diameter was measured using an image analyzer (ImageJ, National Institutes of Health, U.S.A.). For the SEM images of Figure 1 and of Figures 5a, 5b, a JEOL Neoscope JCM-5000 instrument was used. The SEM images in Figures 5c, 5d were recorded with JEOL JSM6010PLUS. The morphology of the samples was also characterized by Transmission Electron Microscopy (TEM) (Tecnai G2 Transmission Electron Microscope $200 \mathrm{kV})$.

The textural characterization of CNFs and ACNFs was studied through $\mathrm{N}_{2}$ physisorption using a Micromeritics Tristar II Plus instrument. The surface area of each sample was calculated using the Brunauer-Emmet-Teller (BET) equation, the total pore volume was determined using the Gurvitch rule at $P / P^{0}=0.95$ and the micropore volume was estimated using the t-plot approach. The X-ray diffraction (XRD) patterns were recorded using a Philips $\mathrm{X}$ 'Pert3 diffractometer with a $\mathrm{Cu}-\mathrm{K} \alpha$ radiation source $(1.54 \AA)$. The peaks were deconvoluted by fitting Lorentzian functions with the aid of a data analysis software (OriginPro). For the XRD measurements, the average interlayer spacing $d_{(002)}$ between consecutive graphene layers was calculated using Bragg's 
equation [31, 32]: $d_{(002)}=\lambda /(2 \cdot \sin \theta)$, where $\lambda$ is the wavelength $(0.154 \mathrm{~nm})$ and $\theta$ is the diffraction angle $\left[{ }^{\circ}\right]$. The crystallite size $L_{\mathrm{c}}$ along the c axis and the size of ab planes $L_{\mathrm{a}}$ was calculated using Scherrer's equations (Equation (1) and (2)) [31, 32]:

$$
\begin{aligned}
& L_{\mathrm{c}}=\frac{0.91 \cdot \lambda}{(F W H M)_{(002)} \cdot \cos \theta_{(002)}} \\
& L_{\mathrm{a}}=\frac{1.84 \cdot \lambda}{(F W H M)_{(100)} \cdot \cos \theta_{(100)}}
\end{aligned}
$$

where FWHM is the full width at half maximum of each peak measured in rad, and it is used for the calculation of $L_{\mathrm{a}}$ and $L_{\mathrm{c}} . N_{\mathrm{c}}$ is the average number of graphene layers in each crystallite (calculated as $\left.N_{\mathrm{c}}=L_{\mathrm{c}} / d_{(002)}\right)$ [31].

Boehm titration was carried out according to the methodology described elsewhere [33, 34]. Briefly, $0.2 \mathrm{~g}$ of the sample were dispersed into $8 \mathrm{ml} \mathrm{NaOH}$ $0.05 \mathrm{M}$ and left under shaking for $24 \mathrm{~h}$. The solution was filtered through syringe filters $(0.22 \mu \mathrm{m})$, an aliquot of $5 \mathrm{ml}$ was added to $10 \mathrm{ml} \mathrm{HCL}$, and the solution was titrated with $\mathrm{NaOH} 0.05 \mathrm{M}$ (titrator base). Bromothymol blue was used as an indicator to determine the equivalent point. The volume of titrator base consumed was measured and converted to $\mathrm{mmol} / \mathrm{g}$ of total surface acidic groups using the methodology described in ref. [33]. A detailed measurement of the relative quantities of each type of acidic group (carboxylic, lactonic and phenolic groups) was not carried out.

All adsorption experiments were conducted in a batch mode. N-dodecane was used as a model diesel fuel and 4,6-dimethyldibenzothiophene (DMDBT) was the refractory sulfur compound of interest. The flasks containing the solutions and the adsorbent were placed in a water bath, at a shaking speed of $105 \mathrm{rpm}$. In all of them, the adsorbent dose was $10 \mathrm{~g} / \mathrm{l}$. This was defined after some preliminary experiments in which different values of the adsorbent dose were tested, and also after an overview of the relevant literature. Particularly, $0.04 \mathrm{~g}$ of the adsorbent were added in each flask containing $4 \mathrm{ml}$ of solution. For the DMDBT, the adsorption equilibrium was investigated for initial concentrations in the range of 100-2000 ppmw, using three different adsorbents: CNFs derived from 50/50 lignin/r-PET carbonized at $1000^{\circ} \mathrm{C}$ with an average diameter close to $400 \mathrm{~nm}$, ACNFs-KOH and ACNFs-KOH-HNO 3 , as they are described in the previous paragraphs. These experiments were performed at room temperature $\left(22^{\circ} \mathrm{C}\right)$, and they were left to equilibrate for $24 \mathrm{~h}$. In order to analyze the results, two different adsorption isotherms were used, namely the Langmuir and Freundlich isotherms.

The Langmuir isotherm is (Equation (3)):

$q_{\mathrm{e}}=q_{\mathrm{m}-\mathrm{L}} \cdot \frac{K_{\mathrm{L}} \cdot C_{\mathrm{e}}}{1+K_{\mathrm{L}} \cdot C_{\mathrm{e}}}$

where $q_{\mathrm{e}}\left[\mathrm{mg}_{\mathrm{DMDBT}} / \mathrm{g}_{\mathrm{C}}\right]$ is the equilibrium adsorption capacity, $C_{\mathrm{e}}\left[\mathrm{mg}_{\mathrm{DMDBT}} / \mathrm{kg}_{\mathrm{C}_{12}}\right]$ is the equilibrium concentration, $q_{\mathrm{m}-\mathrm{L}}\left[\mathrm{mg}_{\mathrm{DMDBT}} / \mathrm{g}_{\mathrm{C}}\right]$ is the maximum adsorption capacity predicted from the Langmuir isotherm and $K_{\mathrm{L}}$ is the Langmuir constant [35-37]. The Freundlich isotherm is (Equation (4)):

$q_{\mathrm{e}}=K_{\mathrm{F}} \cdot C_{\mathrm{e}}^{1 / \mathrm{n}_{\mathrm{F}}}$

where $q_{\mathrm{e}}\left[\mathrm{mg}_{\mathrm{DMDBT}} / \mathrm{g}_{\mathrm{C}}\right]$ is the equilibrium adsorption capacity, $C_{\mathrm{e}}\left[\mathrm{mg}_{\mathrm{DMDBT}} / \mathrm{kg}_{\mathrm{C}_{12}}\right]$ is the equilibrium concentration, $K_{\mathrm{F}}\left[\left(\mathrm{mg}_{\mathrm{DMDBT}} / \mathrm{g}_{\mathrm{C}}\right) /\left(\mathrm{mg}_{\mathrm{DMDBT}} / \mathrm{kg}_{\mathrm{C}}\right)^{1 / \mathrm{n}_{\mathrm{F}}}\right]$ is the Freundlich constant related to the adsorption capacity and $n_{\mathrm{F}}$ (dimensionless) is the Freundlich constant related to the adsorption intensity $[32,35]$.

For ACNFs-KOH-HNO ${ }_{3}$ the adsorption experiments were also conducted at a higher temperature of $50^{\circ} \mathrm{C}$. For the investigation of the kinetics of adsorption of DMDBT on ACNFs-KOH-HNO ${ }_{3}$, an initial concentration of 335 ppmw DMDBT was used. The adsorption capacity was then measured after certain time intervals, at 22 and $50^{\circ} \mathrm{C}$. These experimental results were fitted to two kinetic models; the pseudo-firstorder (Lagergren model) and the pseudo-secondorder (Ho model).

The pseudo-first order kinetic model is (Equation (5)):

$$
\frac{\mathrm{d} q_{\mathrm{t}}}{\mathrm{d} t}=k_{1}\left(q_{\mathrm{e}}-q_{\mathrm{t}}\right) \Leftrightarrow q_{\mathrm{t}}=q_{\mathrm{e}}\left(1-e^{-\mathrm{k}_{\mathrm{1}} \cdot \mathrm{t}}\right)
$$

where $q_{\mathrm{t}}\left[\mathrm{mg}_{\mathrm{DMDBT}} / \mathrm{g}_{\mathrm{C}}[\right.$ is the adsorbed quantity at time $t, q_{\mathrm{e}}\left[\mathrm{mg}_{\mathrm{DMDBT}} / \mathrm{g}_{\mathrm{C}}\right]$ is the equilibrium adsorption and $\left.k_{1}\left[\mathrm{~min}^{-1}\right]\right]$ is the rate constant of the pseudofirst order model $[35,37]$.

The pseudo-second order kinetic model is (Equation (6)):

$$
\begin{aligned}
& \frac{\mathrm{d} q_{\mathrm{t}}}{\mathrm{d} t}=k_{2}\left(q_{\mathrm{e}}-q_{\mathrm{t}}\right)^{2} \Leftrightarrow \\
& q_{\mathrm{t}}=\frac{k_{2} q_{\mathrm{e}}^{2} t}{1+k_{2} q_{\mathrm{e}} t} \Leftrightarrow \frac{t}{q_{\mathrm{t}}}=\frac{1}{k_{2} q_{\mathrm{e}}^{2}}+\frac{t}{q_{\mathrm{e}}}
\end{aligned}
$$


where $q_{\mathrm{t}}\left[\mathrm{mg}_{\mathrm{DMDBT}} / \mathrm{g}_{\mathrm{C}}\right]$ is the adsorbed quantity at time $t, q_{\mathrm{e}}\left[\mathrm{mg}_{\mathrm{DMDBT}} / \mathrm{g}_{\mathrm{C}}\right]$ is the equilibrium adsorption

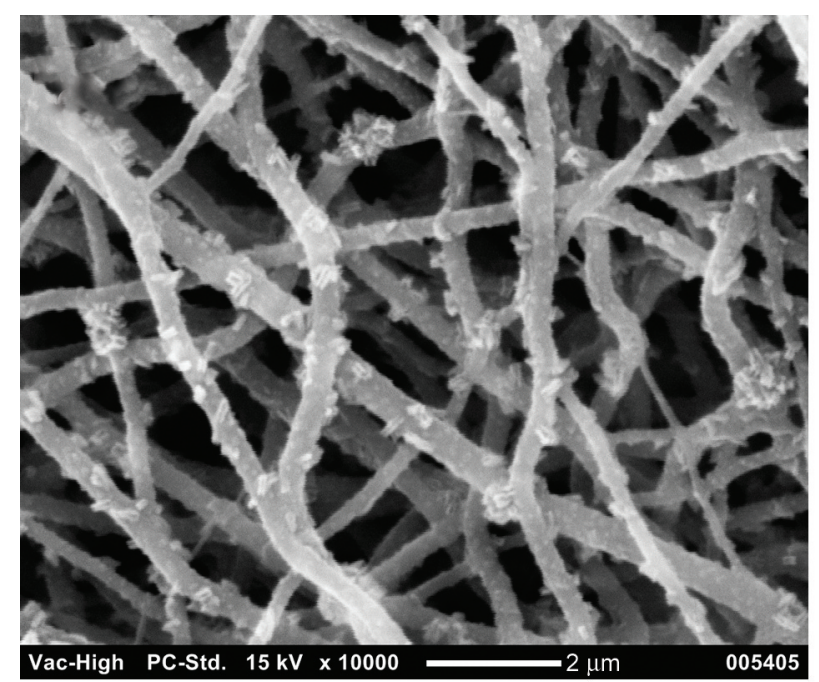

a)

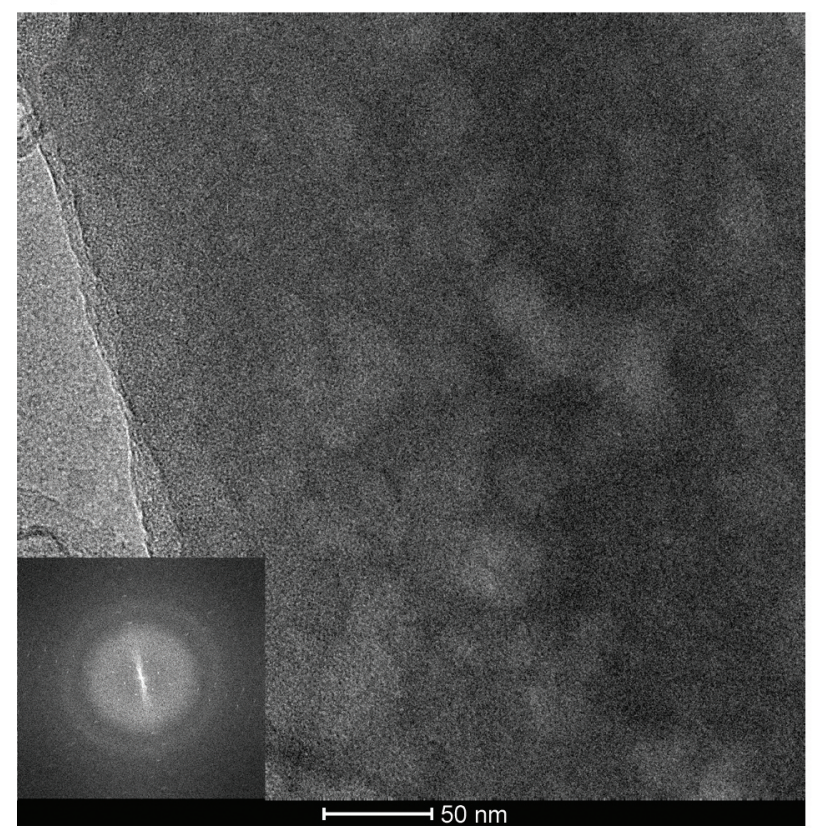

c)

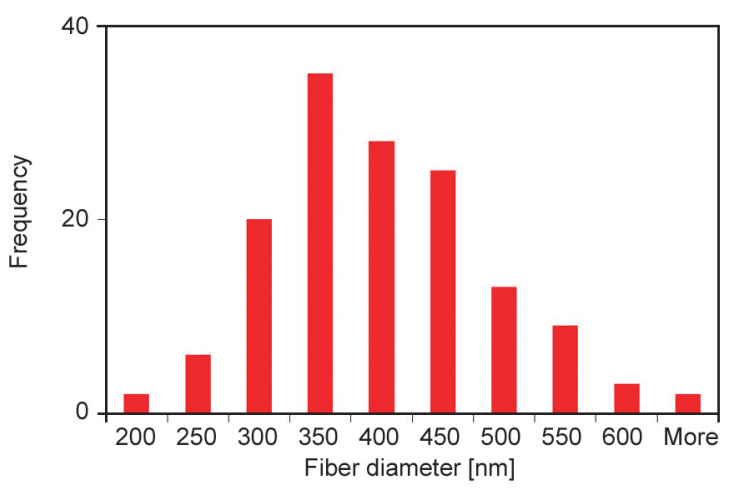

and $k_{2}\left[\mathrm{~g}_{\mathrm{C}} /\left(\mathrm{mg}_{\mathrm{DMDBT}} \cdot \mathrm{min}\right)\right]$ is the rate constant of the pseudo-second order model [35, 37].

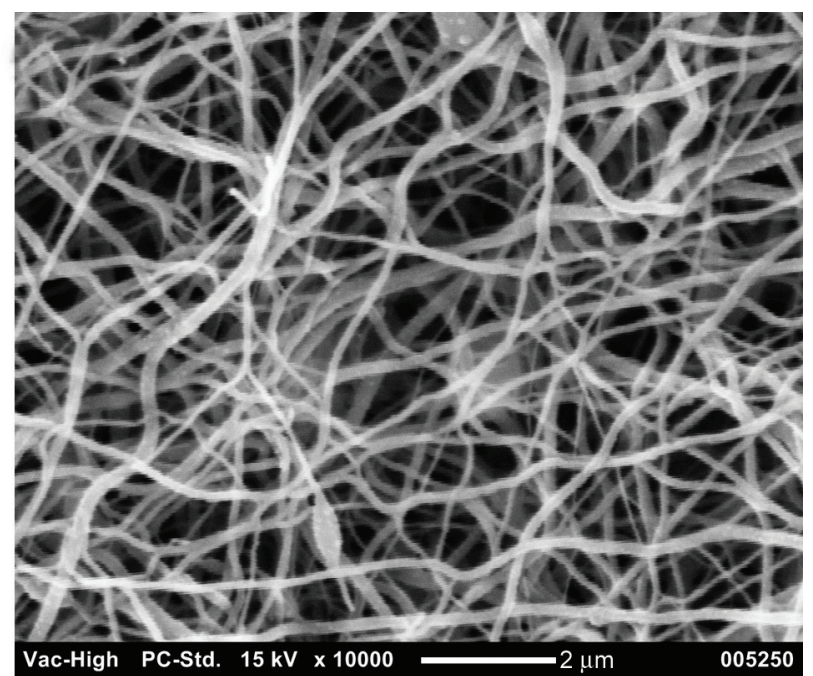

b)

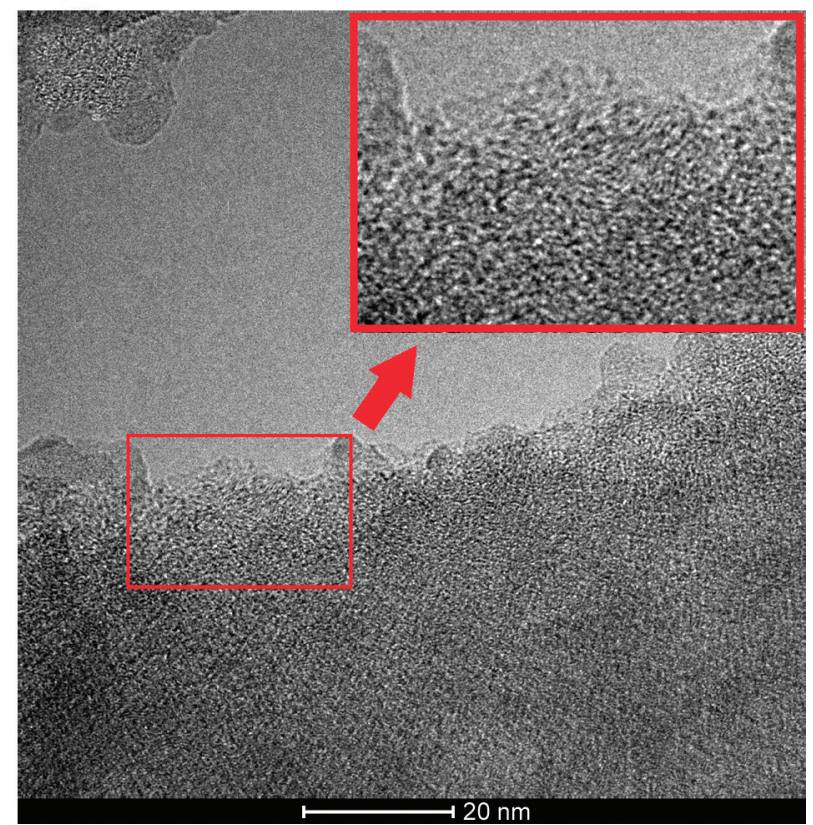

d)

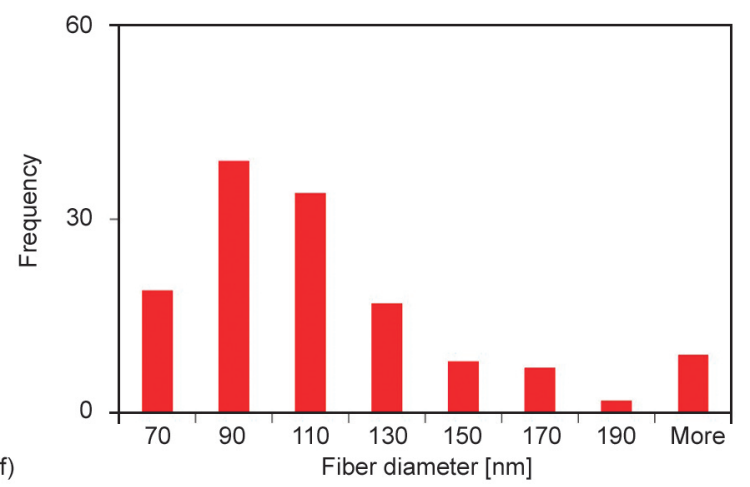

Figure 1. a) and b) show SEM images of electrospun-derived CNFs prepared from a) 50/50 lignin/r-PET (average fiber diameter is $395 \pm 131 \mathrm{~nm}$ ) and b) prepared from 90/10 lignin/r-PET (average fiber diameter is $116 \pm 32 \mathrm{~nm}$ ); the scale bar is $2 \mu \mathrm{m}$; c) and d) show TEM images of CNFs derived from 50/50 lignin/r-PET; the scale bar in c) is $50 \mathrm{~nm}$ and in d) is $20 \mathrm{~nm}$; e) present the fiber diameter distributions of the CNFs prepared from 50/50 and f) 90/10 lignin/r-PET respectively. 
In all the adsorption experiments, the DMDBT concentrations were measured according to the following methodology: the solution was filtered through a syringe filter $(0.22 \mu \mathrm{m})$ after the adsorption process was finished, and the filtrate was transferred to a quartz cuvette. Each solution concentration of DMDBT was measured using UV-Vis spectroscopy (Shimadzu UV 1800) at the wavelength of $313 \mathrm{~nm}$ after a calibration curve was built. After measuring the quantity adsorbed in ppm (mg of solute $/ \mathrm{kg}$ of solvent), the adsorption capacity ' $q$ ' was calculated using the formula $q=$ (ppm adsorbed) $\cdot 0.748 / 10$, where $0.748 \mathrm{~kg} / \mathrm{l}$ is the density of $\mathrm{n}$-dodecane and $10 \mathrm{~g} / \mathrm{l}$ is the adsorbent dose. Thus, the adsorption capacity is measured in $\mathrm{mg}$ of solute per $\mathrm{g}$ of adsorbent $\left[\mathrm{mg}_{\mathrm{DMDBT}} / \mathrm{g}_{\mathrm{C}}\right]$.

\section{Results and discussion}

\subsection{Lignin/r-PET CNFs: porosity and structure}

The lignin/r-PET carbon nanofibers consist of an interconnected network of filaments, as it is shown in the SEM images of Figures 1a and 1b. The TEM images in Figures 1c and 1d show the CNFs prepared from 50/50 lignin/r-PET. It is apparent that the surface of the fibers is rough and it contains protuberances. The randomly oriented, corrugated layers of carbon (Figure 1d) indicate that the CNFs mainly consist of amorphous and disordered structures, although careful examination reveals the existence of spots in which there is parallel stacking of a few graphene layers (inset of Figure 1d). These graphitic domains are, however, very small. Figures $1 \mathrm{e}$ and $1 \mathrm{f}$ present the fiber diameter distributions of the CNFs prepared from 50/50 and 90/10 lignin/r-PET respectively.

The BET surface area measurements revealed that the CNFs prepared from 50/50 lignin/r-PET carbonized at $1000^{\circ} \mathrm{C}$ exhibited the highest BET surface area $\left(353 \mathrm{~m}^{2} / \mathrm{g}\right)$, while the surface area of the CNFs prepared from 90/10 lignin/r-PET doesn't increase more than $115 \mathrm{~m}^{2} / \mathrm{g}$ (Figure 2). Therefore, the presence of r-PET has a positive impact on the development of porosity, due to its more extensive decomposition during carbonization. Similar results have

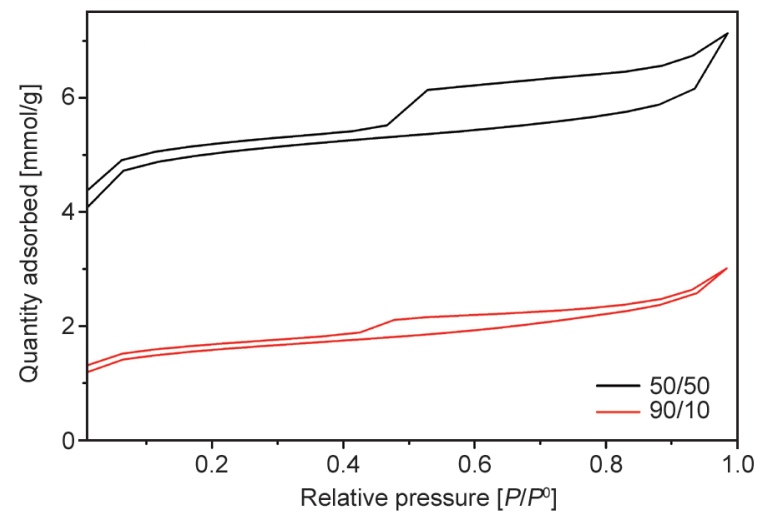

Figure 2. $\mathrm{N}_{2}$ physisorption isotherms of the CNFs prepared from different lignin/r-PET mass ratios (50/50 and $90 / 10)$ at $1000^{\circ} \mathrm{C}$.

been reported elsewhere for PET [13] and also for other polymers [polyvinylpyrrolidone [38], polyvinyl alcohol [39] which were combined with lignin for the preparation of CNFs. The non-closing adsorption/ desorption branches at low relative pressures are an indication of kinetic restrictions in narrow ultra-micropores [40].

The diffractograms of the CNFs are presented in Figure 3. In each graph, two broad peaks which are characteristic of carbon materials are apparent. The peak centered at around $23^{\circ}$ corresponds to the (002) plane of the graphitic lattice, while the peak at around $44^{\circ}$ is associated with its (100) plane (JCPDS number 41-1487) [9,31, 32, 41]. The emergence of

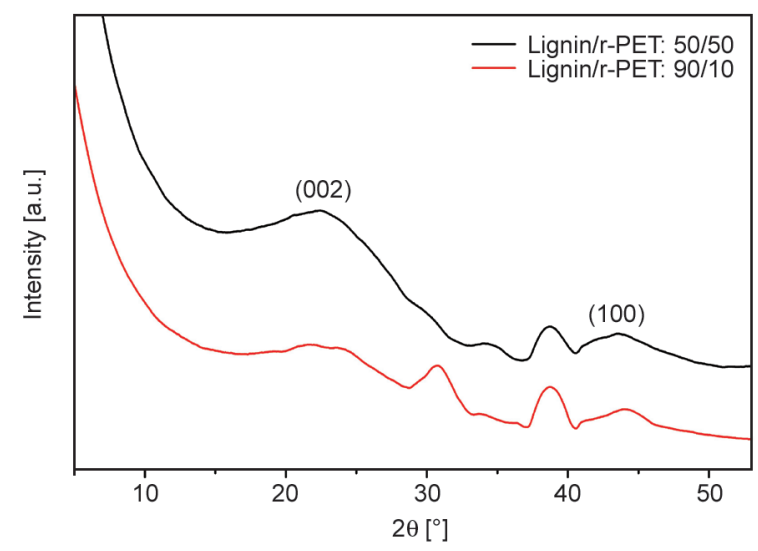

Figure 3. XRD diffractograms of the CNFs prepared from 50/50 and 90/10 lignin/r-PET mass ratios carbonized at $1000^{\circ} \mathrm{C}$.

Table 1. Crystallite features of carbon nanofibers prepared from different lignin/r-PET mass ratios.

\begin{tabular}{|l|c|c|c|c|c|c|c|c|}
\hline $\begin{array}{c}\text { Lignin/r-PET mass ratio } \\
{[\%]}\end{array}$ & $\begin{array}{c}\mathbf{2 \theta}_{(\mathbf{0 0 2})} \\
{\left[{ }^{\circ}\right]}\end{array}$ & $\begin{array}{c}\boldsymbol{d}_{(\mathbf{0 0 2})} \\
{[\mathbf{n m}]}\end{array}$ & $\begin{array}{c}\boldsymbol{F} \boldsymbol{W H} \boldsymbol{M}_{\mathbf{( 2 0 0 )}} \\
{[\mathbf{r a d}]}\end{array}$ & $\begin{array}{c}\boldsymbol{L}_{\mathbf{c}} \\
{[\mathbf{n m}]}\end{array}$ & $\begin{array}{c}\mathbf{2 \theta}_{(\mathbf{1 0 0 )}} \\
{\left[{ }^{\circ}\right]}\end{array}$ & $\begin{array}{c}\boldsymbol{F} \boldsymbol{W H} \boldsymbol{M}_{(\mathbf{1 0 0 )}} \\
{[\mathbf{r a d}]}\end{array}$ & $\begin{array}{c}\boldsymbol{L}_{\mathrm{a}} \\
{[\mathbf{n m}]}\end{array}$ & $\boldsymbol{N}_{\mathbf{c}}$ \\
\hline $50 / 50$ & 23.2 & 0.383 & 0.147 & 0.97 & 43.5 & 0.106 & 2.87 & 2.53 \\
\hline $90 / 10$ & 23.7 & 0.375 & 0.111 & 1.29 & 43.7 & 0.091 & 3.35 & 3.44 \\
\hline
\end{tabular}


these peaks suggests that there are small crystalline graphitic domains inside the CNFs. Particularly, it is shown that the CNFs which are prepared from 90/10 lignin/r-PET have a slightly more ordered structure; their interlayer spacing $d_{(002)}$ is $0.375 \mathrm{~nm}$ while for those prepared from 50/50 lignin/r-PET it is $0.383 \mathrm{~nm}$ (Figure 3 and Table 1). These results agree with the $\mathrm{N}_{2}$ adsorption measurements which showed that the CNFs prepared from 90/10 lignin/r-PET have lower porosity and BET surface area than those prepared from 50/50, hence, fewer voids among their defective graphene layers. The diffraction patterns of the CNFs contain additional obvious peaks between 30 $40^{\circ}$, especially for the CNFs prepared from $90 / 10$ lignin/r-PET. These peaks correspond to impurities deriving from the ash which is present in the starting lignin [42, 43], and they are more intense in the 90/10 sample because its precursor consists of $90 \%$ lignin. These impurities are remnants of the Kraft extraction process [5], and they contain alkali metals, mainly $\mathrm{Na}$. Tedeschi et al. [43] have associated the peaks in this region with $\mathrm{Na}_{2}\left(\mathrm{SO}_{4}\right)$ (ICSD number 98-000-2895).

\subsection{Characterization of the activated CNFs}

After the activation of the CNFs as it is described in Section 2, the BET surface area and the porosity of the ACNFs were measured through $\mathrm{N}_{2}$ physisorption and the results are presented in Table 2 and Figure 4. All the isotherms are type IV with hysteresis loops. The results suggest that the activation raises the porosity of all samples significantly. However, the increase is much higher after activation with $\mathrm{KOH}$ $\left(1413 \mathrm{~m}^{2} / \mathrm{g}\right)$ compared to the activation using $\mathrm{CO}_{2}$ $\left(686 \mathrm{~m}^{2} / \mathrm{g}\right)$. Moreover, the ACNFs-KOH have a narrower average pore width. BET surface areas of this magnitude $\left(>1000 \mathrm{~m}^{2} / \mathrm{g}\right)$ have been reported elsewhere for the chemical activation of $\mathrm{CNF}$ s with $\mathrm{KOH}$ $[11,44]$. Further treatment with $\mathrm{HNO}_{3}$ decreases the BET surface area slightly. This decrease is in accordance with various articles in the literature that report the treatment of activated carbon or CNFs with $\mathrm{HNO}_{3}$ [45-47]. This phenomenon is attributed to the attachment of functional groups on the carbon surface,

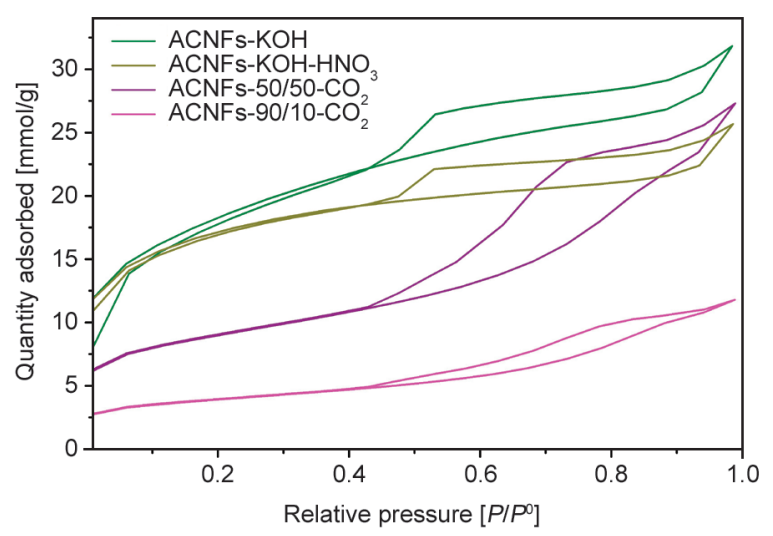

Figure 4. $\mathrm{N}_{2}$ physisorption isotherms of the ACNFs.

which narrows or closes some pores [47]. In addition, this sample (ACNFs-KOH-HNO ${ }_{3}$ ) contains a much higher percentage of microporosity, probably due to the narrowing of small mesopores. This finding is in agreement with the work of Zhou et al. [45] who have reported an increase in microporosity by $70 \%$ after the treatment of activated carbon with $\mathrm{HNO}_{3}$, although the average pore size remained almost stable. Similarly, Yu et al. [46] have reported a decrease in the BET surface area and a narrowing of ultra-micropores after treatment of activated carbon with $\mathrm{HNO}_{3}$. Although it seems that the $\mathrm{HNO}_{3}$ treatment is detrimental to the properties of the adsorbent, it is performed in order to attach oxygen functional groups to the adsorbent surface. This has been proven to be beneficial for the adsorption of sulfur compounds [48-50].

The presence of oxygen on the surface of carbon materials can be determined through Boehm titration. Following the methodology described elsewhere $[33,34]$ and which is briefly summarized in Section 2, it was estimated that the total acidic groups in ACNFs-KOH amount to $1.06 \pm 0.06 \mathrm{mmol} / \mathrm{g}$ while in the $\mathrm{ACNFs}-\mathrm{KOH}-\mathrm{HNO}_{3}$ they amount to $1.78 \pm 0.13 \mathrm{mmol} / \mathrm{g}$ (average of two measurements). Thus, the treatment with $\mathrm{HNO}_{3}$ attaches O-functionalities on the surface of the ACNFs. A more detailed measurement of the relative quantities of each type of acidic group (carboxylic, lactonic and phenolic groups) was not carried out.

Table 2. Textural characteristics of the activated CNFs (ACNFs).

\begin{tabular}{|l|c|c|c|c|c|}
\hline \multicolumn{1}{|c|}{ Sample } & $\begin{array}{c}\text { BET surface area } \\
{\left[\mathbf{m}^{2} / \mathbf{g}\right]}\end{array}$ & $\begin{array}{c}\text { Total pore volume } \\
{\left[\mathbf{c m}^{\mathbf{3}} \mathbf{g}\right]}\end{array}$ & $\begin{array}{c}\text { Micropore volume } \\
{[\mathbf{c m} / \mathbf{g}]}\end{array}$ & $\begin{array}{c}\text { Microporous } \\
{[\mathbf{\%}]}\end{array}$ & $\begin{array}{c}\text { Average pore width } \\
{[\mathbf{n m}]}\end{array}$ \\
\hline $\mathrm{ACNFs}-50 / 50-\mathrm{CO}_{2}$ & 686 & 0.853 & 0.095 & 11.1 & 7.0 \\
\hline $\mathrm{ACNFs}-90 / 10-\mathrm{CO}_{2}$ & 299 & 0.381 & 0.043 & 11.3 & 6.9 \\
\hline $\mathrm{ACNFs}-\mathrm{KOH}$ & 1413 & 1.010 & 0.138 & 13.7 & 3.7 \\
\hline $\mathrm{ACNFs}-\mathrm{KOH}-\mathrm{HNO}_{3}$ & 1267 & 0.811 & 0.261 & 32.2 & 3.4 \\
\hline
\end{tabular}


SEM images of the ACNFs-KOH and the ACNFs$\mathrm{KOH}-\mathrm{HNO}_{3}$ are presented in Figure 5. These samples consist of fibers with an average diameter close to $350-400 \mathrm{~nm}$, which is of similar magnitude to that of the precursor electrospun nanofibers from which they were produced. The fiber diameter distributions of ACNFs-KOH and ACNFs-KOH-HNO 3 are depicted in Figures $5 \mathrm{~g}$ and $5 \mathrm{~h}$ respectively. In Figures $5 \mathrm{e}$ and 5f, TEM images of the ACNFs-KOH sample are presented, as well. As the CNFs lose mass during the activation process, which results in the development of porous channels inside their structure, their density is reduced. Hence, after activation with $\mathrm{KOH}$ and treatment with $\mathrm{HNO}_{3}$, the ACNFs exhibit a very low bulk density, that is, a small amount of ACNFs occupies much space if it is not compacted. Particularly, the bulk density of ACNFs-KOH and ACNFs$\mathrm{KOH}-\mathrm{HNO}_{3}$ was measured to be $\sim 0.075 \mathrm{~g} / \mathrm{ml}$, so, $1 \mathrm{~g}$ of ACNFs occupies $\sim 13.3 \mathrm{ml}$. The bulk density of CNFs manually crashed into powder amounts to $\sim 0.133 \mathrm{~g} / \mathrm{ml}$. For comparison, the bulk density of commercial activated carbon (Merck \#1.02186) was measured to be $0.16 \mathrm{~g} / \mathrm{ml}$.

\subsection{Adsorption of 4,6-DMDBT from a model diesel fuel: equilibrium, kinetics and thermodynamics}

The results presented in the previous section indicate that $\mathrm{ACNF}-\mathrm{KOH}$ and $\mathrm{ACNFs}-\mathrm{KOH}-\mathrm{HNO}_{3}$ possess the highest BET surface area and porosity by far. Hence, these materials were selected to be used for the adsorptive desulfurization experiments. For comparison, the adsorption capacity of the non-activated CNFs prepared from 50/50 lignin/r-PET at $1000^{\circ} \mathrm{C}$ was investigated, as well (the sample characterized in Section 3.1). All experiments were performed in a batch mode, according to the methodology described in Section 2.

The results of the equilibrium adsorption of DMDBT on the three adsorbents at room temperature $\left(22^{\circ} \mathrm{C}\right)$ are presented in Figure 6a. The figure suggests that
ACNFs-KOH- $\mathrm{HNO}_{3}$ exhibit the highest adsorption capacity, while the adsorption capacity of CNFs is very low, as it is expected based on their relatively lower BET surface area. The experimental data were fitted to two different adsorption isotherms, namely the Langmuir and the Freundlich isotherms (Section 2), using non-linear regression with the aid of a data analysis software (OriginPro), and the parameters of the curve fitting can be found in Table 3.

Except for CNFs, in which the Freundlich model gave the best fitting, the adsorption experimental data of the ACNFs were best fitted to the Langmuir model. However, the $R^{2}$ values of the Freundlich model are also high, therefore, they cannot be disregarded. Langmuir isotherm assumes monolayer adsorption on a surface of identical sites [51, 52]. Freundlich isotherm is an empirical model applicable to heterogeneous surfaces or multilayer adsorption, in which $n_{\mathrm{F}}>1$ indicates favorable adsorption [32, 52]. Therefore, the results suggest that there is homogeneous monolayer adsorption, although a heterogeneous mechanism may also be involved, especially at low surface coverage, when the DMDBT molecules first adsorb on the sites of higher energy [37, 53]. A larger value of $K_{\mathrm{F}}$ of the Freundlich isotherm indicates higher adsorption capacity, while a smaller $n_{\mathrm{F}}$ denotes a more homogeneous adsorbent with a narrower site energy distribution [54]. In this case, ACNFs- $\mathrm{KOH}-\mathrm{HNO}_{3}$ seems to have more heterogeneous surface energy, due to the anchoring of more O-functional groups on the carbon surface.

The calculated parameters of the Langmuir isotherm presented in Table 3 show that the ACNFs- $\mathrm{KOH}-$ $\mathrm{HNO}_{3}$ exhibit a maximum adsorption capacity of $120.3 \mathrm{mg}_{\mathrm{DMDBT}} / \mathrm{g}_{\mathrm{C}}$, which corresponds to $18.17 \mathrm{mg} \mathrm{S} / \mathrm{g}_{\mathrm{C}}$. This value is among the highest found in the literature for the adsorption of DMDBT on activated carbon or related carbon-based adsorbents (see Table 4). Table 4 presents a literature overview of the highest values reported for the adsorption of DMDBT on carbon-based adsorbents, as they are

Table 3. Equilibrium adsorption of DMDBT: parameters of the Langmuir and Freundlich isotherms.

\begin{tabular}{|c|c|c|c|c|c|c|c|}
\hline \multirow[b]{2}{*}{ Sample } & \multirow{2}{*}{$\begin{array}{c}\text { Temperature } \\
{\left[{ }^{\circ} \mathrm{C}\right]}\end{array}$} & \multicolumn{3}{|c|}{ Langmuir } & \multicolumn{3}{|l|}{ Freundlich } \\
\hline & & $\begin{array}{c}q_{\mathrm{m}-\mathrm{L}} \\
{\left[\mathrm{mg}_{\mathrm{DMDBT}} / \mathrm{g}_{\mathrm{C}}\right]}\end{array}$ & \begin{tabular}{|c|}
$K_{\mathrm{L}}$ \\
{$\left[\mathrm{kg}_{\mathrm{C}_{12}} / \mathrm{mg}_{\text {DMDBT }]}\right]$}
\end{tabular} & $R^{2}$ & $\begin{array}{c}K_{\mathrm{F}} \\
{\left[\left(\mathrm{mg}_{\text {DMDBT }} / \mathrm{g}_{\mathrm{C}}\right) /\left(\mathrm{mg}_{\text {DMDBT }} / \mathrm{kg}_{\mathrm{C}_{12}}\right)^{1 / \mathrm{n}}\right]}\end{array}$ & $\begin{array}{l}n_{\mathrm{F}} \\
{[-]}\end{array}$ & $R^{2}$ \\
\hline CNFs & 22 & 15.7 & 0.0032 & 0.8891 & 0.49 & 2.12 & 0.9618 \\
\hline ACNFs-KOH & 22 & 95.4 & 0.0088 & 0.9835 & 3.77 & 1.91 & 0.9526 \\
\hline ACNFs-KOH-HNO & 22 & 120.3 & 0.0230 & 0.9800 & 11.18 & 2.43 & 0.9507 \\
\hline ACNFs-KOH-HNO & 50 & 113.9 & 0.0160 & 0.9894 & 7.09 & 2.08 & 0.9706 \\
\hline
\end{tabular}



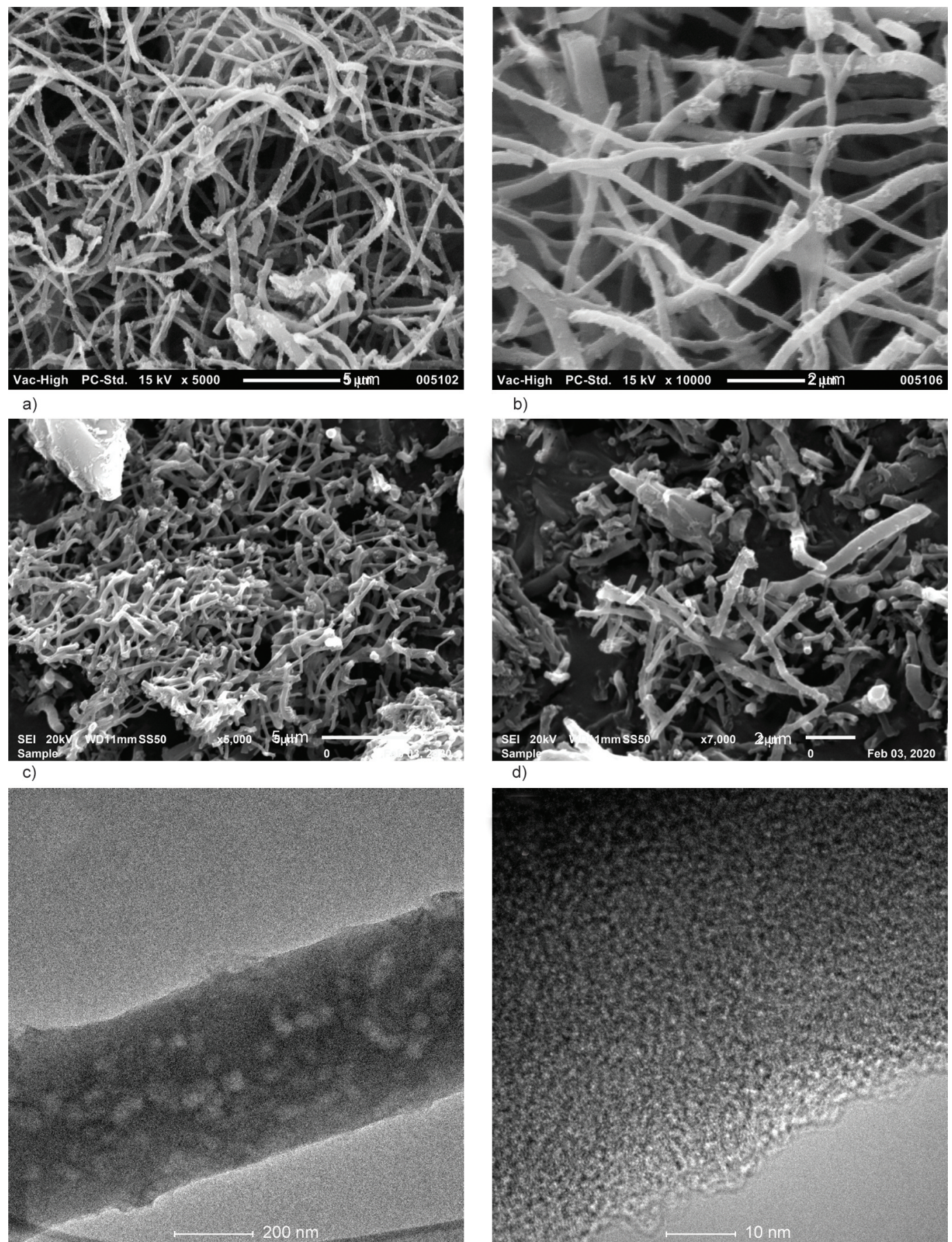

e)

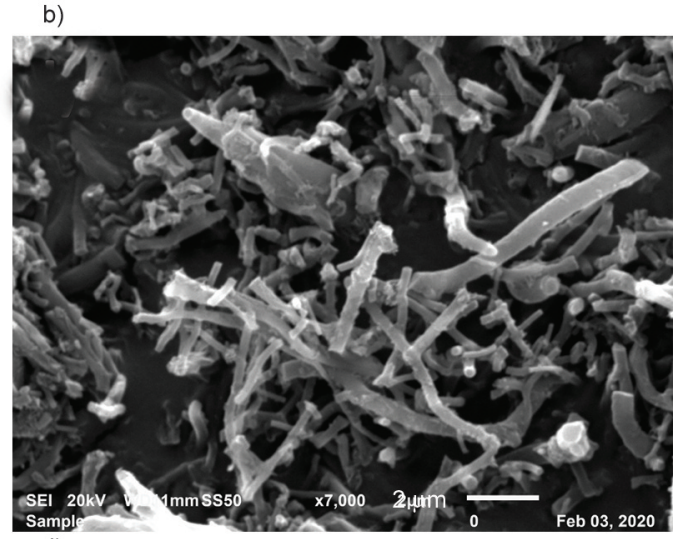

d)

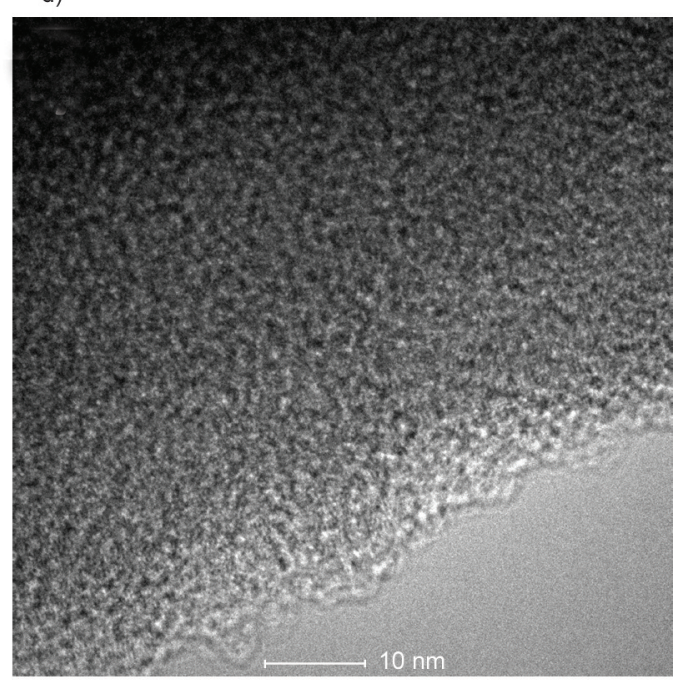

f)
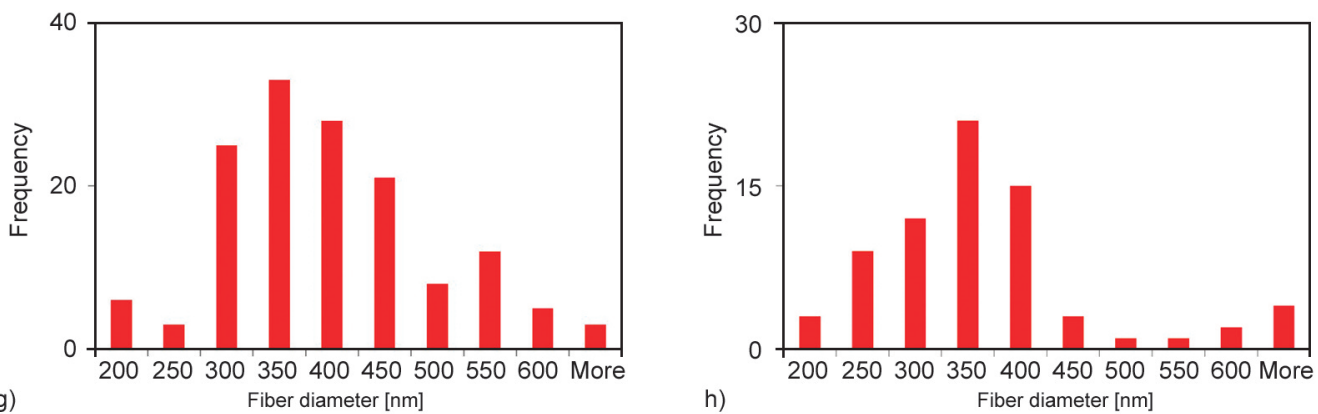

Figure 5. a) and b) SEM images of ACNFs-KOH with $378 \pm 97 \mathrm{~nm}$ average fiber diameter; the scale bar in a) is $5 \mu \mathrm{m}$ and in b) is $2 \mu \mathrm{m}$; c) and d) SEM images of ACNFs-KOH- $\mathrm{HNO}_{3}$ with $356 \pm 105 \mathrm{~nm}$ average fiber diameter; the scale bar in c) is $5 \mu \mathrm{m}$ and in d) is $2 \mu \mathrm{m}$; e) and f) TEM images of ACNFs-KOH; the scale bar in e) is $200 \mathrm{~nm}$ and in f) is $10 \mathrm{~nm} ; \mathrm{g}$ ) and $\mathrm{h}$ ) present the fiber diameter distributions for ACNFs-KOH and $\mathrm{ACNFs}-\mathrm{KOH}-\mathrm{HNO}_{3}$ respectively. 
calculated from the Langmuir isotherm ( $q_{\mathrm{m}-\mathrm{L}}$ values). It should be noted, however, that a direct comparison with the values reported in other studies is not always reliable, as there are various factors that influence the adsorption capacity, such as the dose of the adsorbent, the presence of other solutes and the solvent itself. Very high adsorption capacity values have been reported for the adsorption of DMDBT from hexane, heptane and octane; however, the solubility of DMDBT in these relatively light hydrocarbons is significantly smaller than its solubility in dodecane and hexadecane. Therefore, the removal of DMDBT from light hydrocarbons is more favorable, just as it happens with other refractory S-compounds [55]. As an example, for the case of dibenzothiophene, it has been reported that changing the solvent from $\mathrm{n}$-hexane to $\mathrm{n}$-decane can decrease the maximum adsorption capacity by more than $40 \%$ [55]. Taking this solvent effect into consideration, a comparison of the adsorption capacity found here with the values found in the literature (Table 4) suggests that ACNFs exhibit a high adsorption capacity for DMDBT.

In general, carbon materials have demonstrated a very good adsorption capacity for aromatic S-compounds. These adsorbents are mainly built of carbon atoms connected through $\mathrm{sp}^{2}$-hybridized bonds; hence, they contain conjugated $\pi$-orbitals lying perpendicular to the plane. These out-of-plane conjugated $\pi$-orbitals can generate interactions with other aromatic molecules [48]. On the other hand, thiophenes and benzothiophenes contain aromatic rings, hence, they form $\pi-\pi$ interactions with graphitic substrates. Therefore, the interaction between the delocalized $\pi$-electrons of the aromatic S-compounds and the electron-rich regions of the carbon substrate is based on dispersion forces [48].

The adsorption capacity of ACNFs-KOH is clearly lower than that of the ACNFs-KOH-HNO 3 (95.4 vs. $120.3 \mathrm{mg}_{\mathrm{DMDBT}} / \mathrm{g}_{\mathrm{C}}$ ), although its BET surface area and porosity are higher as it was described in the previous section. The reason is that $\mathrm{ACNFs}-\mathrm{KOH}-\mathrm{HNO}_{3}$ contain much more O-functional groups, which are known to enhance the adsorption of S-compounds $[48,49]$. The various types of thiophenes and benzothiophenes have a basic character as the S-atom acts as an electron donor $[48,66]$. Thus, they interact with the acidic $\mathrm{O}$-groups through Lewis acid-base interactions $[48,49]$, and the treatment with $\mathrm{HNO}_{3}$ enhances the adsorption capacity of the adsorbent $[45,50]$.

Investigation of the adsorption equilibrium at a higher temperature can provide information about the enthalpy of adsorption and the spontaneity of the process. Using the ACNFs-KOH-HNO 3 which gave the highest adsorption capacity, the adsorption of DMDBT was carried out at $50^{\circ} \mathrm{C}$ and the results are presented in Figure 6b. For comparison, the adsorption isotherm at $22^{\circ} \mathrm{C}$ is presented there again, as well. The calculated parameters of the Langmuir and the Freundlich isotherms at $50^{\circ} \mathrm{C}$ are provided in Table 3 . Again, it was found that the Langmuir model fits the data more accurately. The calculated maximum adsorption capacity is $113.9 \mathrm{mg}_{\mathrm{DMDBT}} / \mathrm{g}_{\mathrm{C}}$, which is slightly lower than the adsorption capacity of

Table 4. Equilibrium adsorption of DMDBT on carbon-based adsorbents: literature overview of the adsorption capacity calculated via the Langmuir isotherm.

\begin{tabular}{|l|l|c|c|c|}
\hline \multicolumn{1}{|c|}{ Adsorbent $^{*}$} & \multicolumn{1}{|c|}{ Solvent } & $\begin{array}{c}\text { Adsorption capacity } \\
\text { [mg }_{\text {DMDBT }} \text { /g] }\end{array}$ & $\begin{array}{c}\text { Adsorption capacity } \\
{[\mathbf{m g ~ S / g ] ~}}\end{array}$ & Reference \\
\hline ACNFs & Dodecane & 120.3 & 18.17 & This work \\
\hline AC & Hexadecane & 177.7 & 26.85 & {$[56]$} \\
\hline AC cloth & Heptane & 324.4 & 49.00 & {$[53]$} \\
\hline AC & Hexadecane & 128.7 & 19.50 & {$[51]$} \\
\hline AC doped with Boron & Isooctane & 199.0 & 30.20 & {$[57]$} \\
\hline AC & n-Octane & 385.0 & 58.16 & {$[58]$} \\
\hline AC doped with metals & Decane/hexadecane & 82.9 & 12.50 & {$[59]$} \\
\hline AC & Decane/hexadecane & 84.0 & 12.69 & {$[60]$} \\
\hline AC & Hexadecane & 211.0 & 31.88 & {$[61]$} \\
\hline AC & Hexadecane & 11.3 & 1.71 & {$[62]$} \\
\hline AC & Dodecane & 86.7 & 23.50 & {$[63]$} \\
\hline AC and carbon fibers doped with metals & Hexane & 155.6 & 24.64 & {$[64]$} \\
\hline AC doped with metals & Hexadecane & 163.1 & & {$[65]$} \\
\hline
\end{tabular}



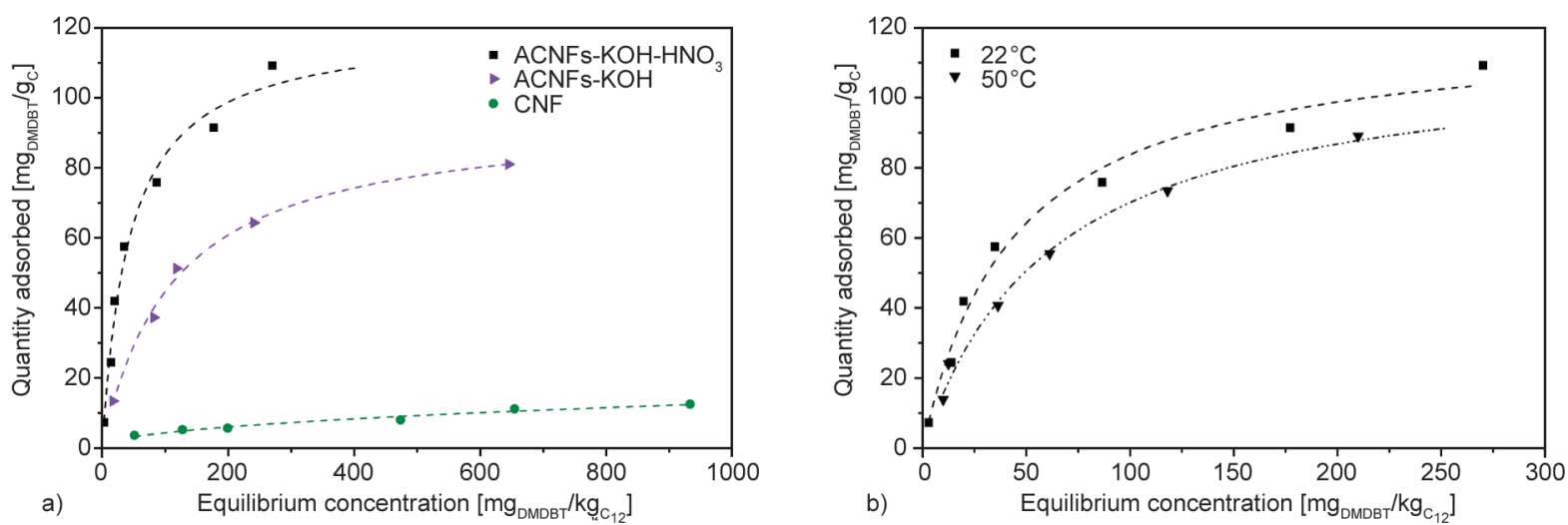

Figure 6. a) Adsorption isotherms of DMDBT on CNFs, ACNFs-KOH and ACNFs-KOH-HNO 3 at $T=22^{\circ} \mathrm{C}$. For all samples, the distinct dots indicate the measured values. The dashed lines in the case of the ACNFs present the fitted Langmuir isotherms, while the dashed line for CNFs presents the fitted Freundlich isotherm; b) Adsorption isotherms of DMDBT on ACNFs-KOH-HNO 3 at 22 and at $50^{\circ} \mathrm{C}$.

ACNFs- $\mathrm{KOH}-\mathrm{HNO}_{3}$ at room temperature. Hence, the process is more favorable at lower temperatures for the range of temperatures studied here. The thermodynamic parameters of the process were calculated using the fundamental equations (Equations (7)-(9)):

$\Delta G^{0}=\Delta H^{0}-T \Delta S^{0}$

$\Delta G^{0}=-R T \ln K_{\mathrm{e}}$

wich give $\ln K_{\mathrm{e}}=-\frac{\Delta H^{0}}{R T}+\frac{\Delta S^{0}}{R}$

where $R$ is the ideal gas constant, $\Delta G^{0}$ is the standard Gibbs free energy change, $\Delta H^{0}$ is the standard enthalpy change and $\Delta S^{0}$ is the standard entropy change. The dimensionless equilibrium constant $K_{\mathrm{e}}$ was calculated following the methodology described in ref. [67]. Briefly, the adsorption can be represented as the following reversible process:

\section{Adsorbate in the solution $\Leftrightarrow$}

Adsorbate on the adsorbent

Therefore, $K_{\mathrm{e}}$ was determined based on the equation $K_{\mathrm{e}}=q_{\mathrm{e}} / C_{\mathrm{e}}$ at different initial concentrations of adsorbate and extrapolating to zero. Then, $\ln K_{\mathrm{e}}$ was plotted against $1 / T$ and after a simple linear regression, it was calculated that $\Delta H^{0}=-8.423 \mathrm{~kJ} / \mathrm{mol}$ and $\Delta S^{0}=$ $0.677 \mathrm{~J} /(\mathrm{mol} \cdot \mathrm{K})$. This value of adsorption enthalpy is lower in absolute value than $-20 \mathrm{~kJ} / \mathrm{mol}$, and this is an indication that the DMDBT molecules are physisorbed on the surface through dispersion forces [68]. Gibbs energy $\Delta G^{0}$ was also calculated for these two temperatures and it was found negative $(-8.623$ and $-8.642 \mathrm{~kJ} / \mathrm{mol}$ for 22 and $50^{\circ} \mathrm{C}$ respectively).
Therefore, the process is spontaneous and exothermic. The positive entropy indicates increased randomness at the solid/solution interface after the adsorption of DMDBT.

Investigation of the adsorption kinetics is very important as this is closely connected to the feasibility of the process at an industrial scale. The adsorption kinetics were studied at 22 and $50^{\circ} \mathrm{C}$, and the results are presented in Figures $7 \mathrm{a}$ and $7 \mathrm{~b}$. Two kinetic models were investigated based on their accuracy to describe the data; the pseudo-first-order kinetic model and the pseudo-second-order kinetic model (see Section 2) [35, 37]. In both cases, it was found that the process is much more accurately described by the pseudo-second-order model (Table 5). The results presented in Figure 7 indicate that the adsorption is remarkably fast. Particularly for room temperature, around $94 \%$ of the final equilibrium adsorption is reached after just $1 \mathrm{~min}$, and $98 \%$ after $10 \mathrm{~min}$. Similarly, at $50^{\circ} \mathrm{C} 99 \%$ of the final equilibrium adsorption is reached after just 15 min. Further proof of the very fast kinetics is provided by the rate constants calculated by fitting the pseudosecond-order model. For $22^{\circ} \mathrm{C}$ the rate constant is $0.297 \mathrm{~g}_{\mathrm{C}} /\left(\mathrm{mg}_{\text {DMDBT }} \cdot \mathrm{min}\right)$, while for $50^{\circ} \mathrm{C}$ the rate constant is $0.316 \mathrm{~g}_{\mathrm{C}} /\left(\mathrm{mg}_{\mathrm{DMDBT}} \cdot \mathrm{min}\right)$, which translates to faster kinetics at higher temperature (Table 5).

Table 6 compares the rate constants calculated here with the highest values found in the literature using the pseudo-second-order kinetic model for the adsorption of DMDBT on carbon-based adsorbents.

Ganiyu et al. [57] have reported very fast kinetics for the adsorption of DMDBT on activated carbon [rate constant $0.514 \mathrm{~g}_{\mathrm{C}} /\left(\mathrm{mg}_{\mathrm{DMDBT}} \cdot \mathrm{min}\right)$ ], however, they report that the experiments were conducted at 

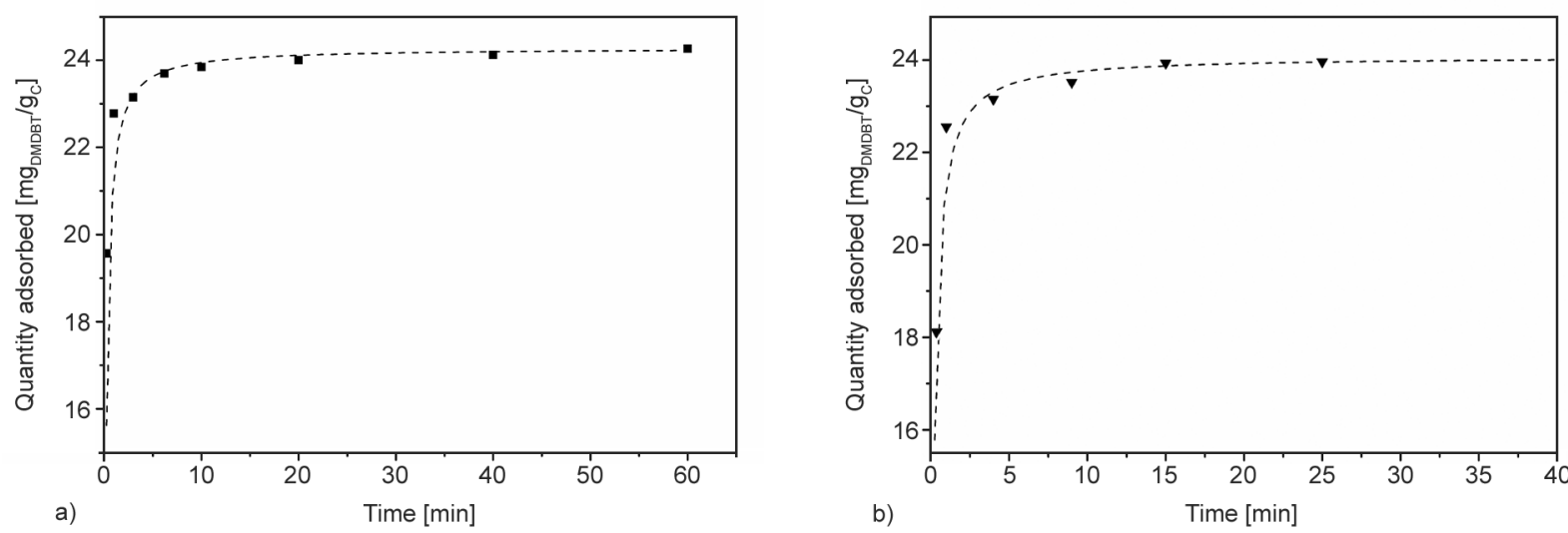

Figure 7. Adsorption kinetics of DMDBT on ACNFs-KOH-HNO 3 : a) at $22^{\circ} \mathrm{C}$ and b) at $50{ }^{\circ} \mathrm{C}$. The dashed lines indicate the fitting of the pseudo-second-order kinetic model.

Table 5. Kinetic parameters for the adsorption of DMDBT on ACNFs-KOH-HNO 3 .

\begin{tabular}{|c|c|c|c|c|c|c|c|}
\hline \multirow{2}{*}{$\begin{array}{c}\text { Temperature } \\
{\left[{ }^{\circ} \mathbf{C}\right]}\end{array}$} & $\begin{array}{c}\boldsymbol{q}_{\mathrm{e}} \text { experimental } \\
{\left[\mathbf{m g}_{\mathrm{DMDBT}} / \mathbf{g}_{\mathrm{C}}\right]}\end{array}$ & $\begin{array}{c}|c| \\
\boldsymbol{q}_{\mathrm{e}} \\
{\left[\mathbf{m g}_{\mathrm{DMDBT}} / \mathbf{g}_{\mathrm{C}}\right]}\end{array}$ & $\begin{array}{c}\boldsymbol{k}_{\mathbf{1}} \\
{\left[\mathbf{m i n}^{-1}\right]}\end{array}$ & $\boldsymbol{R}^{\mathbf{2}}$ & $\begin{array}{c}\boldsymbol{q}_{\mathrm{e}} \\
{\left[\mathbf{m g}_{\mathrm{DMDBT}} / \mathbf{g}_{\mathrm{C}}\right]}\end{array}$ & $\begin{array}{c}\boldsymbol{k}_{\mathbf{2}} \\
{\left[\mathbf{g}_{\mathrm{C}} /\left(\mathbf{m g}_{\mathrm{DMDBT}} \cdot \mathbf{m i n}\right)\right]}\end{array}$ & $\boldsymbol{R}^{\mathbf{2}}$ \\
\hline 22 & 24.25 & 23.70 & 6.97 & 0.8792 & 24.28 & 0.297 & 0.9998 \\
\hline 50 & 24.13 & 23.64 & 3.08 & 0.5768 & 24.08 & 0.316 & 0.9995 \\
\hline
\end{tabular}

Table 6. Comparison of the adsorption kinetics measured here for the adsorption of DMDBT with the highest values found in the literature.

\begin{tabular}{|c|c|c|c|c|c|c|}
\hline Adsorbent & Solvent & \begin{tabular}{|c|} 
Adsorbent dose \\
{$[($ adsorbent mass) $/$} \\
(solution mass or \\
volume)
\end{tabular} & $\begin{array}{c}\text { Initial concentration } \\
\text { of DMDBT }\end{array}$ & $\begin{array}{c}\mathrm{k}_{2} \\
{[\mathrm{~g} /(\mathrm{mg} \cdot \mathrm{min})]}\end{array}$ & Shaking speed & Ref. \\
\hline $\begin{array}{l}\text { Activated carbon } \\
\text { nanofibers }\end{array}$ & Dodecane & $10 \mathrm{~g} / 1$ & $335 \mathrm{ppm}$ & \begin{tabular}{|c|}
0.297 \\
(94\% of equilibrium \\
after just $1 \mathrm{~min}$ ) \\
\end{tabular} & $105 \mathrm{rpm}$ & $\begin{array}{l}\text { This } \\
\text { work }\end{array}$ \\
\hline $\begin{array}{l}\text { Activated carbon } \\
\text { cloth }\end{array}$ & Heptane & $0.02 \mathrm{~g} / 3.5 \mathrm{~g}$ & $\begin{array}{l}200 \mathrm{ppm} \\
\text { (total concentration, } \\
\text { in the presence of } \\
\text { other S-compounds) }\end{array}$ & $\begin{array}{c}0.029 \\
\text { (90\% of equilibrium } \\
\text { after }>40 \mathrm{~min} \text { ) }\end{array}$ & $150 \mathrm{rpm}$ & {$[53]$} \\
\hline $\begin{array}{l}\text { Activated carbon } \\
\text { cloth }\end{array}$ & Heptane & $0.025 \mathrm{~g} / 4 \mathrm{~g}$ & $\begin{array}{c}0.632 \mathrm{mmol} / \mathrm{kg} \\
\text { (in the presence of } \\
\text { other S-compounds) }\end{array}$ & $\begin{array}{c}0.12 \\
\text { (90\% of equilibrium } \\
\text { after }>25 \mathrm{~min})\end{array}$ & N/A & {$[37]$} \\
\hline Activated carbon & Dodecane & $1 \mathrm{~g} / 50 \mathrm{~g}$ & $\begin{array}{c}23.8 \mu \mathrm{mol} / \mathrm{g} \\
\text { (total } \mathrm{S} \text { concentration, } \\
\text { in the presence of } \\
\text { other compounds) }\end{array}$ & $\begin{array}{c}0.3021 \mathrm{mmol} /(\mathrm{g} \cdot \mathrm{min}) \\
(90 \% \text { of equilibrium } \\
\text { after }>30 \mathrm{~min})\end{array}$ & N/A & {$[67]$} \\
\hline $\begin{array}{l}\text { Activated carbon } \\
\text { doped with metals }\end{array}$ & Hexane/toluene & (not stated clearly) & $\begin{array}{c}50 \mathrm{ppm} \\
\text { (in the presence of } \\
\text { other S-compounds) }\end{array}$ & $\begin{array}{c}0.0406 \\
\text { (90\% of equilibrium } \\
\text { after }>20 \mathrm{~min} \text { ) }\end{array}$ & N/A & [69] \\
\hline $\begin{array}{l}\text { Activated carbon } \\
\text { doped with metals }\end{array}$ & Hexane/toluene & (not stated clearly) & $\begin{array}{c}50 \mathrm{ppm} \\
\text { (in the presence of } \\
\text { other S-compounds) }\end{array}$ & $\begin{array}{c}0.0311 \\
\text { (90\% of equilibrium } \\
\text { after } 20 \mathrm{~min} \text { ) }\end{array}$ & N/A & {$[70]$} \\
\hline $\begin{array}{l}\text { Activated carbon } \\
\text { doped with metals }\end{array}$ & Decane/hexadecane & $0.05 \mathrm{~g} / 10 \mathrm{ml}$ & $100 \mathrm{mg} \mathrm{S} / 1$ & $\begin{array}{c}\text { (not calculated) } \\
90 \% \text { of equilibrium } \\
\text { after }>10 \mathrm{~h}\end{array}$ & $110 \mathrm{rpm}$ & [59] \\
\hline Activated carbon & Hexadecane & $0.01 \mathrm{~g} / 1$ & $20 \mathrm{ppm} \mathrm{S}$ & 0.153 & N/A & {$[62]$} \\
\hline $\begin{array}{l}\text { Activated carbon } \\
\text { doped with boron }\end{array}$ & Isooctane & (not clearly stated) & 5-150 ppm S & 0.514 & $300 \mathrm{rpm}$ & {$[57]$} \\
\hline
\end{tabular}


an extreme shaking speed of $300 \mathrm{rpm}$, while isooctane was used as a solvent. Thus, under these conditions, it is expected that very fast kinetics will be measured. Furthermore, when shorter-chain hydrocarbons are used are solvents, much faster adsorption rates are feasible due to a combined influence of their viscosity with the surface tension [55]. In contrast, the experiments in the present study were contacted at a low speed of $105 \mathrm{rpm}$. Therefore, to the best of our knowledge, and based on the information presented in Table 6, the results presented here correspond to comparatively the fastest kinetics that have been reported for the adsorption of DMDBT on a carbonbased adsorbent.

These very fast kinetics are justified by the morphology and structure of the ACNFs. As it was demonstrated in Section 3.2 based on the SEM images of Figure 5 and on the measurements of bulk density, this material actually consists mostly of nano-sized cylinders with high aspect ratio or clusters of them, and it comprises very large voids among the fibers (macropores and large mesopores). Hence, it has a very high specific surface area (the total external surface area of the fibers) which translates into a very large interface between the adsorbent and the solution. This large interface and the large voids among the fibers accelerate the mass transfer of the solutes from the bulk of the solution to the pores of ACNFs, and this is measured as a very high kinetic rate constant.

Based on the adsorption kinetics at the two distinct temperatures, it is possible to calculate the activation energy of the adsorption. The adsorption rate constant $k_{2}$ calculated from the pseudo-second-order model is a function of temperature according to Arrhenius equation [35] (Equation (10)):

$k_{2}=A e^{-\frac{\mathrm{E}_{\mathrm{a}}}{\mathrm{RT}}} \Leftrightarrow \ln k_{2}=\ln A-\frac{E_{\mathrm{a}}}{R T}$

where $E_{\mathrm{a}}[\mathrm{kJ} / \mathrm{mol}]$ is the activation energy, $A$ $\left[\mathrm{g}_{\mathrm{C}} /\left(\mathrm{mg}_{\mathrm{DMDBT}} \cdot \mathrm{min}\right)\right]$ is the collision frequency factor and $R$ is the ideal gas constant. By plotting $\ln k_{2} v s$. $T$ at 295 and $323 \mathrm{~K}$ and fitting a linear relationship, it is calculated that $E_{\mathrm{a}}=1.76 \mathrm{~kJ} / \mathrm{mol}$ and $A=$ $0.607 \mathrm{~g}_{\mathrm{C}} /\left(\mathrm{mg}_{\text {DMDBT }} \cdot \mathrm{min}\right)$. Values of $E_{\mathrm{a}}<4 \mathrm{~kJ} / \mathrm{mol}$ denote physisorption, while $E_{\mathrm{a}}>8 \mathrm{~kJ} / \mathrm{mol}$ is an indication of chemisorption [35]. Thus, this rather small value of $E_{\mathrm{a}}$ calculated here provides further proof that the adsorption of DMDBT on the ACNFs proceeds through dispersion forces.
For validation purposes, a second batch of ACNFs$\mathrm{KOH}-\mathrm{HNO}_{3}$ was produced under the same conditions and it was used to replicate half of the adsorption experiments presented here. In all cases, the adsorption measurements showed very good reproducibility. The equilibrium results obtained from the second batch differed less than $7 \%$ compared to the initial sample, while the adsorption kinetics differed less than $4 \%$.

\section{Conclusions}

In this research, activated carbon nanofibers (ACNFs) were successfully prepared from a blend of lignin with recycled PET and it was demonstrated that they exhibit a high adsorption capacity for the removal of 4,6-dimethyldibenzothiophene (DMDBT) from a model diesel fuel $\left(120.3 \mathrm{mg}_{\mathrm{DMDBT}} / \mathrm{g}_{\mathrm{C}}\right.$ at room temperature). These results practically indicate that ACNFs have the potential to lower a very high concentration of aromatic S-compounds ( $\sim 150 \mathrm{ppm} \mathrm{S})$ to less than $15 \mathrm{ppm}$ as most regulations of commercial fuels demand.

A key feature of this process is the remarkably fast adsorption, as the system reaches $94 \%$ of the equilibrium adsorption capacity after only $1 \mathrm{~min}$ and $98 \%$ after $10 \mathrm{~min}$ at room temperature. These kinetics for the adsorption of DMDBT from model diesel are comparatively the fastest that have been reported under these conditions when a carbon-based adsorbent is used. They are justified by the nano-structured morphology of ACNFs, which comprise a very large specific surface area (the external surface of the fibers) and include a significant volume of mesoand macro-pores. These characteristics render the mass transport of solutes on the carbon surface very fast, a property that is crucial in all adsorption processes. Hence, large fuel quantities can be treated in a very short time.

Besides the adsorption process presented here, the very fast mass transfer is also crucial for energy storage and for catalytic applications, for which ACNFs would be a very promising candidate. In addition, this research serves as a road-map for the manufacture of high added-value products from widely available inexpensive resources.

\section{Acknowledgements}

The authors would like to acknowledge the financial support provided by the Emirates Center for Energy and Environment Research (grant number 31R147). 


\section{References}

[1] Inagaki M., Yang Y., Kang F.: Carbon nanofibers prepared via electrospinning. Advanced Materials, 24, 2547-2566 (2012).

https://doi.org/10.1002/adma.201104940

[2] Zhang B., Kang F., Tarascon J-M., Kim J-K.: Recent advances in electrospun carbon nanofibers and their application in electrochemical energy storage. Progress in Materials Science, 76, 319-380 (2016).

https://doi.org/10.1016/j.pmatsci.2015.08.002

[3] Liang X., Quan B., Chen J., Gu W., Zhang B., Ji G.: Nano bimetallic@carbon layer on porous carbon nanofibers with multiple interfaces for microwave absorption applications. ACS Applied Nano Materials, 1, 5712-5721 (2018).

https://doi.org/10.1021/acsanm.8b01326

[4] Shakoorioskooie M., Menceloglu Y. Z., Unal S., Hayat Soytas S.: Rapid microwave-assisted synthesis of platinum nanoparticles immobilized in electrospun carbon nanofibers for electrochemical catalysis. ACS Applied Nano Materials, 1, 6236-6246 (2018).

https://doi.org/10.1021/acsanm.8b01395

[5] Figueiredo P., Lintinen K., Hirvonen J. T., Kostiainen M. A., Santos H. A.: Properties and chemical modifications of lignin: Towards lignin-based nanomaterials for biomedical applications. Progress in Materials Science, 93, 233-269 (2018).

https://doi.org/10.1016/j.pmatsci.2017.12.001

[6] Duval A., Lawoko M.: A review on lignin-based polymeric, micro- and nano-structured materials. Reactive and Functional Polymers, 85, 78-96 (2014). https://doi.org/10.1016/j.reactfunctpolym.2014.09.017

[7] Schlee P., Hosseinaei O., Baker D., Landmér A., Tomani P., Mostazo-López M., Cazorla-Amóros D., Herou S., Titirici M-M.: From waste to wealth: From kraft lignin to free-standing supercapacitors. Carbon, 145, 470-480 (2019). https://doi.org/10.1016/j.carbon.2019.01.035

[8] Svinterikos E., Zuburtikudis I., Al-Marzouqi M.: Electrospun lignin-derived carbon micro- and nanofibers: A review on precursors, properties, and applications. ACS Sustainable Chemistry and Engineering, 8, 1386813893 (2020).

https://doi.org/10.1021/acssuschemeng.0c03246

[9] Shi Z., Jin G., Wang J., Zhang J.: Free-standing, welded mesoporous carbon nanofibers as anode for high-rate performance Li-ion batteries. Journal of Electroanalytical Chemistry, 795, 26-31 (2017).

https://doi.org/10.1016/j.jelechem.2017.03.047

[10] Beck R. J., Zhao Y., Fong H., Menkhaus T. J.: Electrospun lignin carbon nanofiber membranes with large pores for highly efficient adsorptive water treatment applications. Journal of Water Process Engineering, 16, 240-248 (2017).

https://doi.org/10.1016/j.jwpe.2017.02.002
[11] Hu S., Hsieh Y-L.: Ultrafine microporous and mesoporous activated carbon fibers from alkali lignin. Journal of Materials Chemistry A, 1, 11279-11288 (2013). https://doi.org/10.1039/c3ta12538f

[12] Svinterikos E., Zuburtikudis I., Al-Marzouqi M.: The nanoscale dimension determines the carbonization outcome of electrospun lignin/recycled-PET fibers. Chemical Engineering Science, 202, 26-35 (2019).

https://doi.org/10.1016/j.ces.2019.03.013

[13] Svinterikos E., Zuburtikudis I., Al-Marzouqi M.: Fabricating carbon nanofibers from a lignin/r-PET blend: The synergy of mass ratio with the average fiber diameter. Applied Nanoscience, 10, 1331-1343 (2020). https://doi.org/10.1007/s13204-019-01235-7

[14] Svinterikos E., Zuburtikudis I.: Carbon nanofibers from renewable bioresources (lignin) and a recycled commodity polymer [poly(ethylene terephthalate)]. Journal of Applied Polymer Science, 133, 43936 (2016).

https://doi.org/10.1002/app.43936

[15] Dallmeyer I., Lin L. T., Li Y., Ko F., Kadla J. F.: Preparation and characterization of interconnected, kraft lignin-based carbon fibrous materials by electrospinning. Macromolecular Materials and Engineering, 299, 540-551 (2014). https://doi.org/10.1002/mame.201300148

[16] Ogale A., Zhang M., Jin J.: Recent advances in carbon fibers derived from biobased precursors. Journal of Applied Polymer Science, 133, 43794 (2016). https://doi.org/10.1002/app.43794

[17] Marsh H., Rodríguez-Reinoso F.: Porosity in carbons: Modeling. in 'Activated carbon' (eds.: Marsh H., Rodríguez-Reinoso F.) Elsevier, Oxford, 87-142 (2006). https://doi.org/10.1016/B978-008044463-5/50017-0

[18] Ahmad W.: Sulfur in petroleum: Petroleum desulfurization techniques. in 'Applying nanotechnology to the desulfurization process in petroleum engineering' (eds.: Saleh T. A.) IGI Global, Hershey, 1-52 (2016). https://doi.org/10.4018/978-1-4666-9545-0.ch001

[19] Svinterikos E., Zuburtikudis I., Al-Marzouqi M.: Carbon nanomaterials for the adsorptive desulfurization of fuels. Journal of Nanotechnology, 2019, 2809867 (2019). https://doi.org/10.1155/2019/2809867

[20] Sano Y., Karasawa T., Inomata M., Mochida I., Miyawaki J., Yoon S-H.: Ultra-deep desulfurization process of diesel fuel with adsorption treatment. Journal of the Japan Petroleum Institute, 62, 61-66 (2019).

https://doi.org/10.1627/jpi.62.61

[21] Li J-J., Lu H., Tang X-D., Zhou M., Hu N.: A novel method of preparation-adsorption desulfurization process for dibenzothiophene over sawdust-derived nickel/activated carbon. Petroleum Science and Technology, 36, 456-462 (2018). https://doi.org/10.1080/10916466.2018.1430152 
[22] Saleh T. A., Sulaiman K. O., Al-Hammadi S. A.: Effect of carbon on the hydrodesulfurization activity of MoCo catalysts supported on zeolite/active carbon hybrid supports. Applied Catalysis B: Environmental, 263, 117661 (2020).

https://doi.org/10.1016/j.apcatb.2019.04.062

[23] Saleh T. A.: Carbon nanotube-incorporated alumina as a support for MoNi catalysts for the efficient hydrodesulfurization of thiophenes. Chemical Engineering Journal, 404, 126987 (2021).

https://doi.org/10.1016/j.cej.2020.126987

[24] Ali I., Al-Arfaj A. A., Saleh T. A.: Carbon nanofiberdoped zeolite as support for molybdenum based catalysts for enhanced hydrodesulfurization of dibenzothiophene. Journal of Molecular Liquids, 304, 112376 (2020). https://doi.org/10.1016/j.molliq.2019.112376

[25] Al-Hammadi S. A., Al-Amer A. M., Saleh T. A.: Alumina-carbon nanofiber composite as a support for MoCo catalysts in hydrodesulfurization reactions. Chemical Engineering Journal, 345, 242-251 (2018). https://doi.org/10.1016/j.cej.2018.03.106

[26] Song C., Turaga U., Ma X.: Desulfurization. in 'Encyclopedia of chemical processing' (ed.: Lee S.) Taylor and Francis, New York, 651-662 (2006).

[27] Sun X-L., Liu Z., Cheng Z-L.: Electrospinning fabrication for cloth-like carbon nanofiber films with hierarchical porous structure and their application in deep desulfurization. Ecotoxicology and Environmental Safety, 196, 110555 (2020).

https://doi.org/10.1016/j.ecoenv.2020.110555

[28] Kim S., Bajaj B., Byun C. K., Kwon S-J., Joh H-I., Yi K. B., Lee S.: Preparation of flexible zinc oxide/carbon nanofiber webs for mid-temperature desulfurization. Applied Surface Science, 320, 218-224 (2014).

https://doi.org/10.1016/j.apsusc.2014.09.093

[29] Sun X-L., Liu Z., Cheng Z-L.: Design and fabrication of in-situ $\mathrm{N}$-doped paper-like carbon nanofiber film for thiophene removal from a liquid model fuel. Journal of Hazardous Materials, 389, 121879 (2020).

https://doi.org/10.1016/j.jhazmat.2019.121879

[30] Sun X-L., Liu Z., Cheng Z-L.: A flexible N-doped carbon-nanofiber film reinforced by halloysite nanotubes (HNTs) for adsorptive desulfurization. Journal of Hazardous Materials, 403, 123851 (2021).

https://doi.org/10.1016/j.jhazmat.2020.123851

[31] Ghosh A., do Amaral Razzino C., Dasgupta A., Fujisawa K., Vieira L. H. S., Subramanian S., Costa R. S., Lobo A. O., Ferreira O. P., Robinson J., Terrones M., Terrones H., Viana B. C.: Structural and electrochemical properties of babassu coconut mesocarp-generated activated carbon and few-layer graphene. Carbon, 145, 175-186 (2019).

https://doi.org/10.1016/j.carbon.2018.12.114

[32] Saleh T. A., Danmaliki G. I.: Adsorptive desulfurization of dibenzothiophene from fuels by rubber tyres-derived carbons: Kinetics and isotherms evaluation. Process Safety and Environmental Protection, 102, 9-19 (2016). https://doi.org/10.1016/j.psep.2016.02.005
[33] Goertzen S. L., Thériault K. D., Oickle A. M., Tarasuk A. C., Andreas H. A.: Standardization of the Boehm titration. Part I. $\mathrm{CO}_{2}$ expulsion and endpoint determination. Carbon, 48, 1252-1261 (2010).

https://doi.org/10.1016/j.carbon.2009.11.050

[34] Oickle A. M., Goertzen S. L., Hopper K. R., Abdalla Y. O., Andreas H. A.: Standardization of the Boehm titration: Part II. Method of agitation, effect of filtering and dilute titrant. Carbon, 48, 3313-3322 (2010).

https://doi.org/10.1016/j.carbon.2010.05.004

[35] Soliman A. M., Elwy H. M., Thiemann T., Majedi Y., Labata F. T., Al-Rawashdeh N. A. F.: Removal of Pb(II) ions from aqueous solutions by sulphuric acid-treated palm tree leaves. Journal of the Taiwan Institute of Chemical Engineers, 58, 264-273 (2016).

https://doi.org/10.1016/j.jtice.2015.05.035

[36] Ganiyu S. A., Alhooshani K., Sulaiman K. O., Qamaruddin M., Bakare I. A., Tanimu A., Saleh T. A.: Influence of aluminium impregnation on activated carbon for enhanced desulfurization of DBT at ambient temperature: Role of surface acidity and textural properties. Chemical Engineering Journal, 303, 489-500 (2016). https://doi.org/10.1016/j.cej.2016.06.005

[37] Fallah R. N., Azizian S., Reggers G., Carleer R., Schreurs S., Ahenach J., Meynen V., Yperman J.: Effect of aromatics on the adsorption of thiophenic sulfur compounds from model diesel fuel by activated carbon cloth. Fuel Processing Technology, 119, 278-285 (2014). https://doi.org/10.1016/j.fuproc.2013.11.016

[38] Ma C., Li Z., Li J., Fan Q., Wu L., Shi J., Song Y.: Lignin-based hierarchical porous carbon nanofiber films with superior performance in supercapacitors. Applied Surface Science, 456, 568-576 (2018).

https://doi.org/10.1016/j.apsusc.2018.06.189

[39] Ago M., Borghei M., Haataja J. S., Rojas O. J.: Mesoporous carbon soft-templated from lignin nanofiber networks: Microphase separation boosts supercapacitance in conductive electrodes. RSC Advances, 6, 8580285810 (2016).

https://doi.org/10.1039/c6ra17536h

[40] Cychosz K. A., Thommes M.: Progress in the physisorption characterization of nanoporous gas storage materials. Engineering, 4, 559-566 (2018).

https://doi.org/10.1016/j.eng.2018.06.001

[41] Roman J., Neri W., Derré A., Poulin P.: Electrospun lignin-based twisted carbon nanofibers for potential microelectrodes applications. Carbon, 145, 556-564 (2019). https://doi.org/10.1016/j.carbon.2019.01.036

[42] Chen M., Hao W., Ma R., Ma X., Yang L., Yan F., Cui K., Chen H., Li Y.: Catalytic ethanolysis of Kraft lignin to small-molecular liquid products over an alumina supported molybdenum nitride catalyst. Catalysis Today, 298, 9-15 (2017).

https://doi.org/10.1016/j.cattod.2017.08.012 
[43] Tedeschi G., Guzman-Puyol S., Ceseracciu L., Paul U. C., Picone P., Di Carlo M., Athanassiou A., HerediaGuerrero J. A.: Multifunctional bioplastics inspired by wood composition: Effect of hydrolyzed lignin addition to xylan-cellulose matrices. Biomacromolecules, 21, 910-920 (2020).

https://doi.org/10.1021/acs.biomac.9b01569

[44] Song M., Yu L., Song B., Meng F., Tang X.: Alkali promoted the adsorption of toluene by adjusting the surface properties of lignin-derived carbon fibers. Environmental Science and Pollution Research, 26, 22284-22294 (2019).

https://doi.org/10.1007/s11356-019-05456-9

[45] Zhou A., Ma X., Song C.: Effects of oxidative modification of carbon surface on the adsorption of sulfur compounds in diesel fuel. Applied Catalysis B: Environmental, 87, 190-199 (2009). https://doi.org/10.1016/j.apcatb.2008.09.024

[46] Yu C., Fan X., Yu L., Bandosz T. J., Zhao Z., Qiu J.: Adsorptive removal of thiophenic compounds from oils by activated carbon modified with concentrated nitric acid. Energy and Fuels, 27, 1499-1505 (2013). https://doi.org/10.1021/ef400029b

[47] Nordin N. A., Rahman N. A., Abdullah A. H.: Effective removal of $\mathrm{Pb}(\mathrm{II})$ ions by electrospun $\mathrm{PAN} /$ sago ligninbased activated carbon nanofibers. Molecules, 25, 3081 (2020). https://doi.org/10.3390/molecules25133081

[48] Saleh T. A., Danmaliki G. I.: Influence of acidic and basic treatments of activated carbon derived from waste rubber tires on adsorptive desulfurization of thiophenes. Journal of the Taiwan Institute of Chemical Engineers, 60, 460-468 (2016). https://doi.org/10.1016/j.jtice.2015.11.008

[49] Yu M., Li Z., Ji Q., Wang S., Su D., Lin Y. S.: Effect of thermal oxidation of activated carbon surface on its adsorption towards dibenzothiophene. Chemical Engineering Journal, 148, 242-247 (2009).

https://doi.org/10.1016/j.cej.2008.08.018

[50] Song H., Gao J., Chen X., He J., Li C.: Removal of thiophenic sulfur compounds from oil using chlorinated polymers and Lewis acid mixture via adsorption and Friedel-crafts alkylation reaction. Chinese Journal of Chemical Engineering, 22, 713-720 (2014).

https://doi.org/10.1016/S1004-9541(14)60093-8

[51] Triantafyllidis K. S., Deliyanni E. A.: Desulfurization of diesel fuels: Adsorption of 4,6-DMDBT on different origin and surface chemistry nanoporous activated carbons. Chemical Engineering Journal, 236, 406-414 (2014).

https://doi.org/10.1016/j.cej.2013.09.099

[52] Nunthaprechachan T., Pengpanich S., Hunsom M.: Adsorptive desulfurization of dibenzothiophene by sewage sludge-derived activated carbon. Chemical Engineering Journal, 228, 263-271 (2013). https://doi.org/10.1016/j.cej.2013.04.067
[53] Fallah R. N., Azizian S.: Removal of thiophenic compounds from liquid fuel by different modified activated carbon cloths. Fuel Processing Technology, 93, 45-52 (2012).

https://doi.org/10.1016/j.fuproc.2011.09.012

[54] Wang Q., Liang X., Qiao W., Liu C., Liu X., Zhan L., Ling L.: Preparation of polystyrene-based activated carbon spheres with high surface area and their adsorption to dibenzothiophene. Fuel Processing Technology, 90, 381-387 (2009).

https://doi.org/10.1016/j.fuproc.2008.10.008

[55] Kumagai S., Ishizawa H., Toida Y.: Influence of solvent type on dibenzothiophene adsorption onto activated carbon fiber and granular coconut-shell activated carbon. Fuel, 89, 365-371 (2010).

https://doi.org/10.1016/j.fuel.2009.08.013

[56] Seredych M., Deliyanni E., Bandosz T. J.: Role of microporosity and surface chemistry in adsorption of 4,6dimethyldibenzothiophene on polymer-derived activated carbons. Fuel, 89, 1499-1507 (2010).

https://doi.org/10.1016/j.fuel.2009.09.032

[57] Ganiyu S. A., Ajumobi O. O., Lateef S. A., Sulaiman K. O., Bakare I. A., Qamaruddin M., Alhooshani K.: Boron-doped activated carbon as efficient and selective adsorbent for ultra-deep desulfurization of 4,6-dimethyldibenzothiophene. Chemical Engineering Journal, 321, 651-661 (2017).

https://doi.org/10.1016/j.cej.2017.03.132

[58] Khan N. A., An H. J., Yoo D. K., Jhung S. H.: Polyaniline-derived porous carbons: Remarkable adsorbent for removal of various hazardous organics from both aqueous and non-aqueous media. Journal of Hazardous Materials, 360, 163-171 (2018).

https://doi.org/10.1016/j.jhazmat.2018.08.001

[59] Arcibar-Orozco J. A., Acosta-Herrera A. A., RangelMendez J. R.: Simultaneous desulfuration and denitrogenation of model diesel fuel by Fe-Mn microwave modified activated carbon: Iron crystalline habit influence on adsorption capacity. Journal of Cleaner Production, 218, 69-82 (2019).

https://doi.org/10.1016/j.jclepro.2019.01.202

[60] Shalaby C., Ma X., Zhou A., Song C.: Preparation of organic sulfur adsorbent from coal for adsorption of dibenzothiophene-type compounds in diesel fuel. Energy and Fuels, 23, 2620-2627 (2009).

https://doi.org/10.1021/ef801135t

[61] Deliyanni E., Seredych M., Bandosz T. J.: Interactions of 4,6-dimethyldibenzothiophene with the surface of activated carbons. Langmuir, 25, 9302-9312 (2009). https://doi.org/10.1021/la900854x

[62] Kampouraki Z. C., Giannakoudakis D. A., Triantafyllidis K. S., Deliyanni E. A.: Catalytic oxidative desulfurization of a 4,6-DMDBT containing model fuel by metalfree activated carbons: The key role of surface chemistry. Green Chemistry, 21, 6685-6698 (2019). https://doi.org/10.1039/c9gc03234g 
[63] Iruretagoyena D., Bikane K., Sunny N., Lu H., Kazarian S. G., Chadwick D., Pini R., Shah N.: Enhanced selective adsorption desulfurization on $\mathrm{CO}_{2}$ and steam treated activated carbons: Equilibria and kinetics. Chemical Engineering Journal, 379, 122356 (2020). https://doi.org/10.1016/j.cej.2019.122356

[64] Moosavi E. S., Dastgheib S. A., Karimzadeh R.: Adsorption of thiophenic compounds from model diesel fuel using copper and nickel impregnated activated carbons. Energies, 5, 4233-4250 (2012). https://doi.org/10.3390/en5104233

[65] Iravani A. A., Gunda K., Ng F. T. T.: Adsorptive removal of refractory sulfur compounds by tantalum oxide modified activated carbons. AIChE Journal, 63, 50445053 (2017).

https://doi.org/10.1002/aic.15852

[66] Seredych M., Rawlins J., Bandosz T. J.: Investigation of the thermal regeneration efficiency of activated carbons used in the desulfurization of model diesel fuel. Industrial and Engineering Chemistry Research, 50, 14097-14104 (2011).

https://doi.org/10.1021/ie202159a
[67] Wen J., Han X., Lin H., Zheng Y., Chu W.: A critical study on the adsorption of heterocyclic sulfur and nitrogen compounds by activated carbon: Equilibrium, kinetics and thermodynamics. Chemical Engineering Journal, 164, 29-36 (2010).

https://doi.org/10.1016/j.cej.2010.07.068

[68] Atkins P., de Paula J.: Physical chemistry. W. H. Freeman and Company, New York, 876-908 (2010).

[69] Saleh T. A.: Simultaneous adsorptive desulfurization of diesel fuel over bimetallic nanoparticles loaded on activated carbon. Journal of Cleaner Production, 172, 2123-2132 (2018). https://doi.org/10.1016/j.jclepro.2017.11.208

[70] Saleh T. A., Al-Hammadi S. A., Tanimu A., Alhooshani K.: Ultra-deep adsorptive desulfurization of fuels on cobalt and molybdenum nanoparticles loaded on activated carbon derived from waste rubber. Journal of Colloid and Interface Science, 513, 779-787 (2018). https://doi.org/10.1016/j.jcis.2017.11.076 